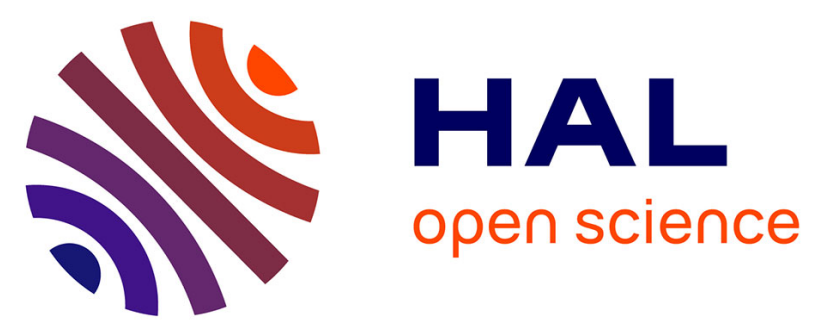

\title{
Nickel oxide selectively deposited on the 101 facet of anatase TiO2 nanocrystal bipyramids for enhanced photocatalysis
}

Shun Kashiwaya, Céline Olivier, Jérôme Majimel, Andreas Klein, Wolfram Jaegermann, Thierry Toupance

\section{To cite this version:}

Shun Kashiwaya, Céline Olivier, Jérôme Majimel, Andreas Klein, Wolfram Jaegermann, et al.. Nickel oxide selectively deposited on the 101 facet of anatase $\mathrm{TiO} 2$ nanocrystal bipyramids for enhanced photocatalysis. ACS Applied Nano Materials, 2019, 2 (8), pp.4793-4803. 10.1021/acsanm.9b00729 . hal-03060262

\section{HAL Id: hal-03060262 https://hal.science/hal-03060262}

Submitted on 29 Jan 2021

HAL is a multi-disciplinary open access archive for the deposit and dissemination of scientific research documents, whether they are published or not. The documents may come from teaching and research institutions in France or abroad, or from public or private research centers.
L'archive ouverte pluridisciplinaire $\mathbf{H A L}$, est destinée au dépôt et à la diffusion de documents scientifiques de niveau recherche, publiés ou non, émanant des établissements d'enseignement et de recherche français ou étrangers, des laboratoires publics ou privés. 


\title{
Nickel oxide selectively deposited on the $\{101\}$ facet of anatase $\mathrm{TiO}_{2}$ nanocrystal bipyramids for enhanced photocatalysis
}

\author{
Shun Kashiwaya ${ }^{\mathrm{a}, \mathrm{b}}$, Céline Olivier ${ }^{\mathrm{a}}$, Jérôme Majimel ${ }^{\mathrm{c}}$, Andreas Klein ${ }^{\mathrm{b}}$, Wolfram Jaegermann ${ }^{\mathrm{b}}$, and Thierry \\ Toupance $^{\mathrm{a}^{*}}$ \\ a Institut des Sciences Moléculaires, UMR 5255 CNRS, Université de Bordeaux, 351 Cours de la Libération, 33405 Talence, France \\ ${ }^{b}$ Fachbereich Material- und Geowissenshaften, Technische Universität Darmstadt, Petersenstr. 23, 64287 Darmstadt, Germany \\ ${ }^{\mathrm{c}}$ CNRS, Université de Bordeaux, ICMCB, UMR 5026, 87 Avenue du Dr. Albert Schweitzer, Pessac Cedex, Bordeaux 33608 F, France
}

\begin{abstract}
Facet-engineered anatase $\mathrm{TiO}_{2}$ with $\mathrm{NiO}$ nanoparticles heterocontacts were successfully prepared by selective photodeposition of $\mathrm{NiO}$ nanoparticles onto the $\{101\}$ facet of the top-truncated bipyramidal $\mathrm{TiO}_{2}$ anatase nanocrystals coexposed with $\{001\}$ and $\{101\}$ facets. The morphology and electronic properties of the resulting $0.1-10 \mathrm{wt} \% \mathrm{NiO}^{-\mathrm{decorated}} \mathrm{TiO} \mathrm{were}$ investigated by X-ray diffraction, high-resolution electron microscopy, $\mathrm{N}_{2}$ sorption analysis, and UV-vis spectroscopy. Furthermore, a careful determination of the energy band alignment diagram was conducted by a model experiment using XPS and UPS to verify charge separation at the interface of the $\mathrm{NiO}-\mathrm{TiO}_{2}$ heterostructure. The model experiment was performed by stepwise deposition of $\mathrm{NiO}$ onto oriented $\mathrm{TiO}_{2}$ substrates and in-situ photoelectron spectroscopy measurements without breaking vacuum. Core levels showed shifts of $0.58 \mathrm{eV}$ toward lower binding energies, meaning an upward band bending in $\mathrm{TiO}_{2}$ at the $\mathrm{NiO}-\mathrm{TiO}_{2}$ interface. Furthermore, 0.1 wt $\% \mathrm{NiO}-\mathrm{TiO}_{2}$ exhibited $50 \%$ higher activities than the pure $\mathrm{TiO}_{2}$ for methylene blue (MB) photodecomposition under UV irradiation. This enhanced photocatalytic activity of $\mathrm{NiO}-\mathrm{TiO}_{2}$ nanocomposites was related to the internal electric field developed at the $\mathrm{p}-\mathrm{n} \mathrm{NiO}-\mathrm{TiO}_{2}$ heterojunction, leading to vectorial charge separation. Finally, mechanistic studies conducted in the presence of carrier or radical scavengers revealed that holes dominantly contributed to the photocatalytic reactions in the case of $\mathrm{NiO}-\mathrm{TiO}_{2}$ photocatalysts while electrons played the main role in photocatalysis for the pure $\mathrm{TiO}_{2}$ materials.
\end{abstract}

Keywords : Facet-engineered NiO-anatase $\mathrm{TiO}_{2}$ materials ; Interface experiments ; Band alignment diagrams ; Photocatalysis ; Organic dyes

*E-mail: thierry.toupance@u-bordeaux.fr / More by Thierry Toupance / http://orcid.org/0000-0001-8234-7064 (corresponding author)

\section{Introduction}

Chemical reactions on titanium dioxide $\left(\mathrm{TiO}_{2}\right)$ surfaces have attracted worldwide attention in the fields of energy conversion,(1-3) energy storage,(4,5) and photocatalysis(6-8) because of the relatively high abundance, low cost, environmental friendliness, high chemical stability, and both outstanding optical and electronic properties of $\mathrm{TiO}_{2}$-based systems. Thus, $\mathrm{TiO}_{2}$ materials, mainly as anatase polymorph, showed a great ability for decomposition of various pollutants in air or water,(7) carbon dioxide reduction,(9) and water splitting(6) under light illumination. Nonetheless, pure $\mathrm{TiO}_{2}$ materials still suffer from some limitations for practical use in photocatalysis stemming from too fast recombination of photogenerated electron-hole pairs and too slow redox reactions.(10) A first efficient way to improve the photocatalytic activity consists in building heterojunction nanocomposites combining $\mathrm{TiO}_{2}$ nanostructures with other metals $(7,11,12)$ or semiconductors. $(13-16)$ For instance, coupling $\mathrm{TiO}_{2}$ to noble metal cocatalysts with large work function, e.g., platinum and rhodium, enables to enhance the photogeneration quantum yield in minority carriers by separating electron-hole pairs with a Schottky barrier at the interface and subsequently transferring them to acceptor molecules. $(7,11,12)$ Furthermore, along with providing reaction sites, these noble metals have beneficial effects on the kinetics of the photocatalytic reactions, for instance, by decreasing the overpotential and the activation energy for hydrogen evolution from water according to the volcano plot for metal-hydrogen bonding energy.(17) However, the use of noble metals led to further drawbacks such as their scarcity and cost and their ability to catalyze the back-reaction of the formation of water from hydrogen and oxygen, limiting the photocatalytic activity for water splitting. Thus, transition metal oxides that have a negligible activity for water formation have been chosen as cocatalysts to avoid back-reactions.(18) 
On the other hand, the selective deposition of $\mathrm{Pt}$ and $\mathrm{PbO}_{2}$ on specific orientations of rutile and anatase particles was first reported by Ohno et al.,(19) revealing that the different facets of a crystal exposed to the surface promote the separation of photoinduced electrons and holes.(20-23) More recently, this approach was also exploited to obtain dual heterojunction photocatalysts(24) or spatially separated bicocatalysts onto $\mathrm{TiO}_{2} .(25)$ These findings have therefore triggered crystal facet engineering of $\mathrm{TiO}_{2}$ particles. Crystallographic surface orientation and structures indeed play a crucial role in photocatalysis with metal oxide semiconductors since the surface atomic structures rule the physisorption/chemisorption of reactive species, surface transfer and trapping of photoinduced charge carriers, and, as a consequence, redox processes.(26) Over the past decade, many efforts have been devoted to maximizing the surface area of the highest energy $\{001\}$ facet of anatase crystals, which was believed to be the most reactive, to reach high photocatalytic efficiencies.(27-29) By contrast, improved photocatalytic efficiencies were reported for particles exposing both low-energy facets $\{101\}$ as reduction reaction sites and high-energy facets $\{001\}$ as oxidation reaction sites.(30-33) These findings were recently related to the lower Fermi level of the $\{001\}$ facets compared to that of the $\{101\}$ facets which induces a potential difference at the interface between both facets, favoring the spatial separation of the photogenerated electrons and holes.(34) As a result, the presence of both $\{101\}$ and $\{001\}$ facets in anatase nanocrystals is relevant to obtain high photocatalytic activities. Moreover, enhanced photocatalytic activities could be reached with $\mathrm{TiO}_{2}$-based materials via the formation of a $\mathrm{p}-\mathrm{n}$ heterojunction by combining appropriate $\mathrm{p}$-type metal oxide cocatalysts together with facet engineering of $\mathrm{TiO}_{2}$ nanocrystals for their synergetic effect.(12) In this context, nickel oxide $(\mathrm{NiO})$, which is rather abundant and reactive, is one of the most investigated cocatalysts in combination with $\mathrm{TiO}_{2}$ and can act as both reduction and oxidation cocatalysts. Thus, various $\mathrm{NiO}_{-} \mathrm{TiO}_{2}$ nanostructures with a random distribution of $\mathrm{NiO}$ onto $\mathrm{TiO} \mathrm{O}_{2}$ have been reported which led to improved photocatalytic properties for pollutant degradation(35-41) or hydrogen production. $(37,42,43)$ However, the selective deposition of $\mathrm{NiO}$ onto oriented $\mathrm{TiO}_{2}$ nanoparticles has never been achieved, and both electronic and photocatalytic properties of the resulting heterostructures have not been investigated yet. Furthermore, even though different energy band alignments at the $\mathrm{NiO}-\mathrm{TiO}_{2}$ interface have been proposed for $\mathrm{NiO}$ species randomly distributed onto nanoparticles $\mathrm{TiO}_{2},(40,43,44)$ the energy band alignment of well-defined NiO-anatase $(101)$ and NiO-anastase (001) interfaces still remains unknown.

In the following, we described the selective deposition of $\mathrm{NiO}$ onto the $\{101\}$ facet of anatase $\mathrm{TiO}_{2}$ nanoparticles coexposed with $\{001\}$ and $\{101\}$ facets by employing an original photodeposition method. The formation of cubic NiO particles on the $\{101\}$ facet was clearly evidenced by high-resolution transmission electron microscopy (HRTEM), high-resolution scanning transmission electron microscopy (HRSTEM), and energy dispersive X-ray spectroscopy (EDX) mapping. Furthermore, a so-called interface experiment(45) was performed by in-situ X-ray (XPS) and ultraviolet (UPS) photoelectron spectroscopy measurements during stepwise $\mathrm{NiO}$ deposition via dc sputtering onto a stoichiometric single crystal anatase (101) surface. An energy band alignment of the NiO-anatase (101) interface was experimentally derived from the obtained XP and UP spectra of the interface experiment. Finally, photocatalytic activities of the obtained nanocomposites as a function of NiO loading were examined by degradation of methylene blue (MB) under UV irradiation, and mechanistic aspects were investigated by comparing the degradation rate determined with those obtained in the presence of hole and radical scavengers. The main species ruling the photocatalytic properties of the $\mathrm{NiO}-\mathrm{TiO}_{2}$ nanomaterials appeared to be different from that governing those of pure $\mathrm{TiO}_{2}$ nanocrystals.

\section{Experimental section}

\subsection{Photocatalysts preparation}

All the chemicals were purchased in analytical grade and used without any further purification. Crystalline $\mathrm{TiO}_{2}$ anatase particles coexposed with $\{001\}$ and $\{101\}$ facets obtained by gas-phase reaction were provided by Prof. Ohtani's group.(31,46) According to SEM images recorded at different magnifications, the shape of these nanoparticles is rather uniform (Figure S1). NiO-TiO 2 anatase heterostructured photocatalysts were synthesized in two steps. First, Ni-B was selectively deposited onto the $\{101\}$ facet of the anatase particles by photodeposition.(47) $1.27 \mathrm{~g}$ of boric acid (Sigma-Aldrich) was added to $70 \mathrm{~mL}$ of distilled water under stirring. The solution was sonicated for $5 \mathrm{~min}$. Potassium hydroxide was then progressively added to the solution until reaching $\mathrm{pH}=9.2$ under stirring, and $30 \mathrm{~mL}$ of distilled water was added to the solution. The resulting solution is referred as a KBi buffer. The KBi buffer, deionized water, and nickel(II) nitrate hexahydrate solution (34 mM, Sigma-Aldrich) were stirred and subsequently centrifuged at $4000 \mathrm{rpm}$ for $10 \mathrm{~min}$ to remove a slight amount of precipitated nickel hydroxide, which has a lightgreen color. $500 \mathrm{mg}$ of the single crystalline anatase particles was dispersed into the solution, treated with sonication for 10 min, and stirred for $1 \mathrm{~h}$. To realize the photodeposition of Ni-B onto the anatase particles, the solution was irradiated by UV light under stirring for $3 \mathrm{~h}$. After washing with distilled water three times, the resulting particles were dried at $70{ }^{\circ} \mathrm{C}$ and dried under vacuum for $1 \mathrm{~h}$ to obtain $\mathrm{Ni}-\mathrm{B}$ deposited onto the $\{101\}$ facet of the anatase particles. The $\{101\}$ facet of anatase crystals was found to accumulate photogenerated electrons, $(20)$ and thus nickel nitrate $\left(\mathrm{Ni}^{2+}\right)$ is supposed to be reduced to $\mathrm{Ni}-\mathrm{B}(\mathrm{Ni})$ selectively on the $\{101\}$ facet of anatase crystals under UV irradiation. The resulting $\mathrm{Ni}-\mathrm{B} / \mathrm{TiO}_{2}$ heterostructured particles were 
then annealed at $400{ }^{\circ} \mathrm{C}$ for $4 \mathrm{~h}$ to oxidize deposited $\mathrm{Ni}-\mathrm{B}$ and achieve the target $\mathrm{NiO}-\mathrm{TiO}_{2}$ photocatalysts where $\mathrm{NiO}$ is selectively deposited onto the $\{101\}$ facet of the anatase particles coexposed with $\{001\}$ and $\{101\}$ facets. Photocatalysts containing $0.1,0,2,0.5,1$, and $10 \mathrm{wt} \%$ of $\mathrm{NiO}$ were obtained by adding $0.2,0.4,1,2$, and $20 \mathrm{~mL}$ of nickel nitrate solution $(34$ $\mathrm{mM})$, respectively, as a precursor added to $500 \mathrm{mg}$ of anatase particles. The KBi buffer/nickel nitrate solution ratio was fixed at 2.5 , and distilled water was also added to reach $100 \mathrm{~mL}$ of the total volume of the precursor solution containing KBi buffer and nickel nitrate. The resulting photocatalysts are hereafter named $0.1 \mathrm{wt} \% \mathrm{NiO}-\mathrm{TiO}_{2}, 0.2 \mathrm{wt} \% \mathrm{NiO}_{-} \mathrm{TiO}_{2}, 0.5 \mathrm{wt} \% \mathrm{NiO}^{-\mathrm{TiO}}, 1 \mathrm{wt}$ $\% \mathrm{NiO}-\mathrm{TiO}_{2}$, and 10 wt \% $\mathrm{NiO}-\mathrm{TiO}_{2}$.

\subsection{Photocatalyst characterization}

XRD analyses were performed using a Bruker AXS diffractometer (D2 PHASER A26-X1-A2B0D3A) equipped with a Cu anode (K $\alpha$ radiation).(48) DRS spectra were recorded with an UV-vis-NIR Cary 5000E spectrophotometer endowed with an integrating sphere and by using a Suprasil cell bearing a quartz window. Halon standard ( $6 \mathrm{~mm}$ deep and $1 \mathrm{~g} \mathrm{~cm}^{-3}$ density) was employed as a reference. Specific surface areas $\left(S_{\mathrm{BET}}\right)$ were determined by applying the BET (Brunauer-Emmett-Teller) equation(49) between 0.1 and 0.3 relative pressures of $\mathrm{N}_{2}$ adsorption-desorption isotherms recorded at $77 \mathrm{~K}$ with an ASAP2010 Micromeritics apparatus. HRTEM images were taken with a JEOL JEM 2200F (JEOL, Tokyo, Japan) operating at an acceleration voltage of $200 \mathrm{kV}$ (wavelength $\lambda=2.51 \mathrm{pm}$ ) equipped with a Schottky type FEG and an EDX system (Oxford, Wiesbaden, Germany). For the sample preparation for HRTEM, HRSTEM, and EDX, the photocatalysts nanoparticles were dispersed in ethanol under ultrasound sonication, and a few droplets of the suspension were placed on holey carbon grids (Cu-300HD, Pacific Grid-Tech).

Electronic properties of the synthesized photocatalysts were investigated with DAISY-MAT(50) consisting of a multitechnique surface analysis system (Physical Electronics PHI 5700). XP spectra were measured by using monochromatic Al Ka (1486.6 eV) radiation with an energy resolution of $0.4 \mathrm{eV}$ as determined from the broadening of the Fermi edge of a sputter-cleaned $\mathrm{Ag}$ substrate. Binding energies of core levels and the valence band maximum $E_{\mathrm{VB}}$ can be obtained with an accuracy of 50 meV and $100 \mathrm{meV}$, respectively. Binding energies determined by XPS were calibrated by the Fermi level position of the sputter-cleaned Ag sample. Thus, all binding energies are provided with respect to the calibrated Fermi level set to 0 eV. Photocatalyst samples were pressed onto indium foils as a conductive substrate to avoid a charging problem and transferred into the XPS chamber without any further treatments.

\subsection{Photocatalyst experiments}

Photocatalytic properties of the different $\mathrm{NiO}-\mathrm{TiO}_{2}$ nanocomposites were determined by decomposition of $\mathrm{MB}$ (Alfa Aesar) under UV-light illumination using a previously established procedure.(51) Typically, a suspension of photocatalyst (50 mg) in a $\mathrm{MB}$ aqueous solution ( $10 \mathrm{mg} / \mathrm{L}, 50 \mathrm{~mL}$ ) was introduced into a Pyrex beaker and was then illuminated with a $125 \mathrm{~W}$ high-pressure mercury lamp (Philips, HPL-N $125 \mathrm{~W} / 542 \mathrm{E} 27$ ) positioned $60 \mathrm{~mm}$ above the solution. After stirring in the dark for 30 min to reach adsorption/desorption equilibrium and switching on the light, $2 \mathrm{~mL}$ of the suspensions was collected at given irradiation time intervals and then centrifuged $(4000 \mathrm{rpm}, 10 \mathrm{~min}$ ) to remove the photocatalyst particles from the MB solution. The remaining MB amount was monitored by UV-vis spectroscopy following the change in absorption at $\lambda_{\max }=664 \mathrm{~nm}$ by using a Shimadzu UV-1650 pc spectrophotometer. Blank experiments were also conducted with catalysts in the dark and without catalysts under light irradiation.

Furthermore, the same experiments were reproduced in the presence of different scavengers for charge carriers and radicals to investigate the role of radicals in the photocatalytic reactions. Potassium iodide (KI), isopropanol (IPA), and 1,4-benzoquinone (BQ) were selected as holes, hydroxyl radicals $(\mathrm{OH})$, and superoxide radicals $\left({ }^{\circ} \mathrm{O}^{2-}\right)$ scavengers, respectively.(52-55) The concentration of $\mathrm{KI}, \mathrm{IPA}$, and $\mathrm{BQ}$ was $4 \times 10^{-4}, 1 \times 10^{-3}$, and $1 \times 10^{-3} \mathrm{M}$, respectively.

\subsection{Interface model experiment}

Natural anatase crystals were employed for both (101) and (001) surfaces (SurfaceNet GmbH, Germany). The size of the substrates is $5 \times 5 \times 1 \mathrm{~mm}^{3}$. A surface roughness less than a lattice constant was achieved after epi-polishing. As-is surfaces are contaminated from the air and the polishing step. Cleaning cycles of $\mathrm{Ar}^{+}$ion sputtering with an energy of $1 \mathrm{keV}$ for $15 \mathrm{~min}$ and annealing under vacuum at $873 \mathrm{~K}$ for $30 \mathrm{~min}$ were repeated until no remaining emissions from contaminations were observed

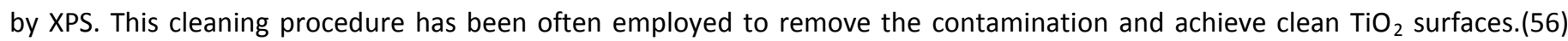
However, Ar sputtering not only leads to a highly reduced surface, and thus forms $\mathrm{O}$ vacancies and $\mathrm{Ti}^{3+}$ surface states, but also partially ruins the crystallinity of the surface and introduces an amorphous phase.(57) The $O$ vacancy concentration for the (101) and (001) surfaces prepared by the procedure is expected to be $7 \pm 2 \%$ and $1 \pm 2 \%$, respectively. (58) Therefore, the sputtered surfaces were oxidized by an $\mathrm{O}$ plasma at room temperature in an atmosphere of $7.5 \times 10^{-5}$ mbar $\mathrm{O}_{2}$ for 15 min to reoxidize the surface and subsequently annealed at $873 \mathrm{~K}$ in UHV to recrystallize the surface. Here the $\mathrm{O}$ plasma was selected to replenish the 
lattice $\mathrm{O}$ instead of annealing in $\mathrm{O}_{2}$ atmosphere, which has been generally used for oxidation, as this annealing procedure can form additional incomplete reconstructions for rutile surfaces,(59) which could be also formed for anatase surfaces. It may also result in iron oxide surface contaminations as at elevated temperatures Fe surface segregation, which is typical contamination in natural anatase crystals, may take place.(57) Furthermore, atomic $\mathrm{O}$ in the $\mathrm{O}$ plasma is more oxidative than a molecular $\mathrm{O}_{2}$ during annealing in an $\mathrm{O}$ atmosphere.(60) The reoxidized and recrystallized surfaces were treated with an $\mathrm{O}$ plasma at the same conditions mentioned above to oxidized them as they were slightly reduced due to annealing under vacuum at the elevated temperature. This further oxidation procedure is expected to introduce adsorbed $\mathrm{O}$ atoms such as peroxo species adsorbed on the surfaces. Finally, the stoichiometric surfaces were obtained by removing adsorbed $\mathrm{O}$ atoms by annealing the oxidized surfaces in UHV condition at $473 \mathrm{~K}$ for $20 \mathrm{~min} .(61)$

To experimentally determine energy band alignments of $\mathrm{NiO}$ and oriented anatase surfaces, the interface model experiments were performed in DAISY-MAT capable of XPS and UPS and different deposition chambers in UHV without breaking the vacuum. This system allowed the in-situ characterization of the prepared surfaces and interfaces. NiO was grown on the stoichiometric anatase (001) and (101) substrates by using a direct current (dc) reactive magnetron sputter deposition from a metallic Ni target with $40 \mathrm{~W}$ of dc power under a $20 \% \mathrm{O}_{2} / 80 \%$ Ar mixture atmosphere at 0.5 Pa pressure and room temperature. The gas flow of oxygen and argon was kept at 4 and $16 \mathrm{sccm}$, respectively, during the deposition. The target-to-substrate distance was set to 8.4 $\mathrm{cm}$. The deposition rate was about $2.0 \mathrm{~nm} \mathrm{~min}^{-1}$. We are aware of possible additional defect states induced by sputter deposition of oxides. However, a number of systematic studies on different oxides have proven that for our experimental conditions this approach is applicable. After each stepwise deposition of NiO by dc sputtering onto the substrates, XPS spectra were recorded without breaking the vacuum to follow shifts of the binding energies of core level emission lines and the evolution of peak shapes. To determine work function and ionization potentials of the stoichiometric anatase substrates and $\mathrm{NiO}$ films at the end of all the stepwise deposition, UPS spectra were recorded in normal emission with He I radiation ( $h v=21.2$ eV) from a He discharge lamp and a negative sample bias of $4.0 \mathrm{~V}$. The total energy resolution of UPS was $0.2 \mathrm{eV}$. No charging problems were observed during the XPS and UPS measurements. Binding energies obtained by XPS and UPS were calibrated by the Fermi level energy of the sputter-cleaned Ag sample. Hence, all the binding energies are given with respect to the calibrated Fermi level position set to $0 \mathrm{eV}$. More details of the DAISY-MAT system and the experimental approach in performing the experiments may be found elsewhere.(45)

\section{Results and discussion}

\subsection{Characterization of photocatalysts}

To prepare well-defined heterostructure $\mathrm{NiO}-\mathrm{TiO}_{2}$ particles, the electroless nickel plating strategy was adapted to deposit amorphous $\mathrm{Ni}-\mathrm{B}$ catalyst on specific facets of $\mathrm{TiO}_{2}$ nanocrystals.(47) Instead of using silver-based materials as a reducing agent, UV-light combined with the charge separation offered by the different redox properties of $\{101\}$ and $\{001\}$ facets were exploited for the selective deposition of amorphous $\mathrm{Ni}-\mathrm{B}$ on the $\{101\}$ facets which led to NiO particles after further calcination (Scheme $1)$.

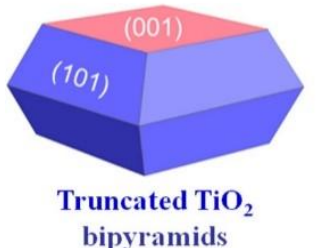

bipyramids

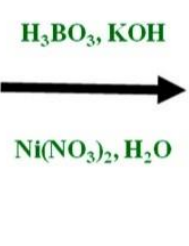

Truted Ni-B/TiO bipyramids hv (U.V)
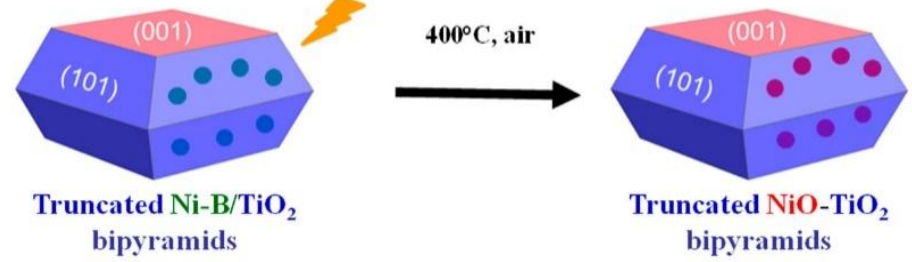

Scheme 1. Preparation Strategy for Selective Deposition of NiO onto $\{101\}$ Anatase $\mathrm{TiO}_{2}$ Facets

Regardless of the NiO loading, the main diffraction peaks observed in the XRD patterns can be indexed as the (101), (004), (200), (105), (211), (204), (116), (220), and (215) diffraction lines of the anatase phase of $\mathrm{TiO}_{2}$ (Figure 1). The weak feature at 27.5 (20) can be attributed to the presence of small amounts of the rutile polymorph (110 diffraction line) due to the high temperature $(1573 \mathrm{~K})$ used to synthesize the oriented $\mathrm{TiO}_{2}$ particles. $(31,46)$ Peaks assigned to $\mathrm{NiO}$ were not observed clearly probably due to the small crystalline domain size (nanometers order) of the NiO species. It is indeed well-known that the crystallite size is inversely proportional to the full width at half-maximum ( $\mathrm{fwhm}$ ) of each peak, which yields broadened and attenuated signals in the XRD patterns.(62) 


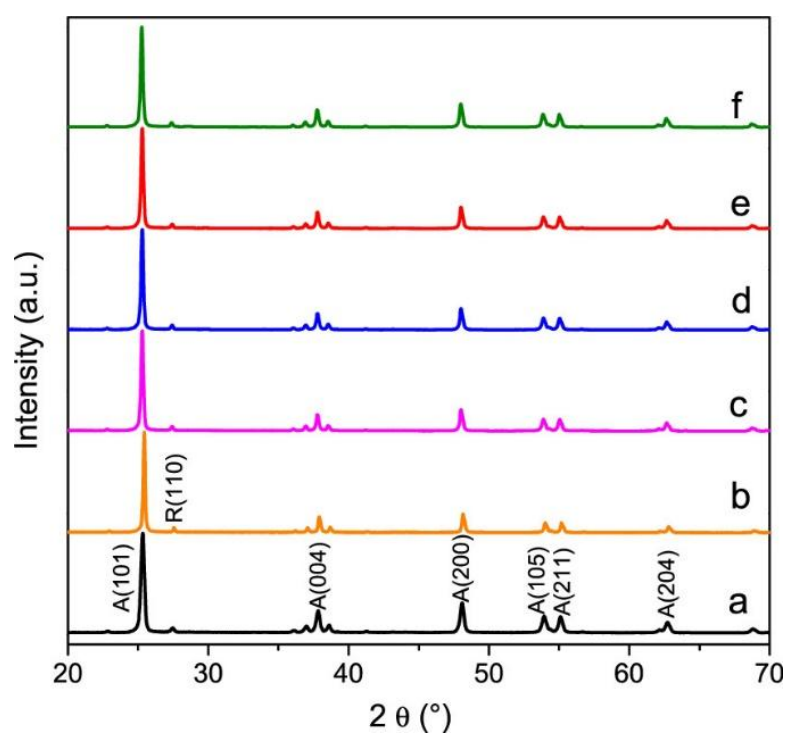

Figure 1. XRD patterns of the pure $\mathrm{TiO}_{2}$ (a, black), 0.1 (b, orange), 0.2 (c, magenta), 0.5 (d, blue), 1.0 (e, red), and 10 wt \% (f, olive) NiO-TiO 2 composites.

The morphology of the different materials was then studied by TEM, HR-TEM, and EDX analyses (Figures 2 and 3). A square shape of the particle indicates that the $\{001\}$ facet of the anatase single crystal is parallel to the sample carbon grid as anatase single crystals coexposed with $\{001\}$ and $\{101\}$ facets have a bipyramidal shape with truncation of their top and bottom edges (Figure 2A). A gradation of the contrast observed at the edge of the particle can be caused by thinner parts of the sample and might represent a slope of the $\{101\}$ facet. Figure $2 \mathrm{~B}$ shows $\mathrm{TiO}_{2}$ particles with other angles showing both $\{001\}$ and $\{101\}$ facets. STEM images, EDX elemental mapping, and HR-TEM images of 10 wt \% NiO- $\mathrm{TiO}_{2}$ depicted in Figure 3 clearly indicate that $\mathrm{Ni}$ elements are selectively distributed at the $\{101\}$ facets, which constitute the edge of the particle (Figures 3E and 3F). HR-TEM images confirm the selective deposition of $2-3 \mathrm{~nm}$ of $\mathrm{NiO}$ particles onto the $\{101\}$ facet (Figures $3 \mathrm{G}$ and $3 \mathrm{H}$ ). The interplanar spacings of 0.18 and $0.20 \mathrm{~nm}$ match with the $\{200\}$ and $\{111\}$ planes of the face-centered cubic (fcc) crystalline phase of NiO. STEM images before and after electron beam irradiation also indicate the selective deposition of $\mathrm{NiO}$ onto the $\{101\}$ facet of anatase (Figures $3 \mathrm{~A}$ and $\mathrm{BB}$ ). Moreover, selected area diffraction patterns clearly confirm that NiO particles were selectively deposited on the $\{101\}$ anatase facet, with no diffraction feature typical of NiO being detected on the $\{001\}$ anatase facet (Figure S2).
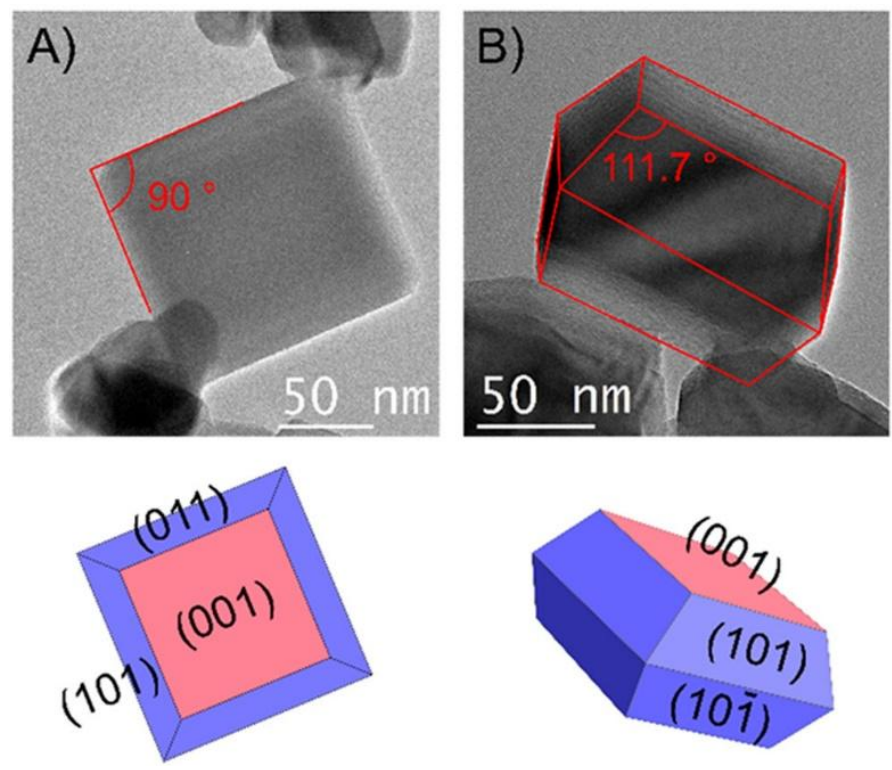

Figure 2. Bright-field TEM images of the pure $\mathrm{TiO}_{2}$ recorded along $(A)$ the [001] zone axis and $(B)$ the tilted along the [010] direction. 

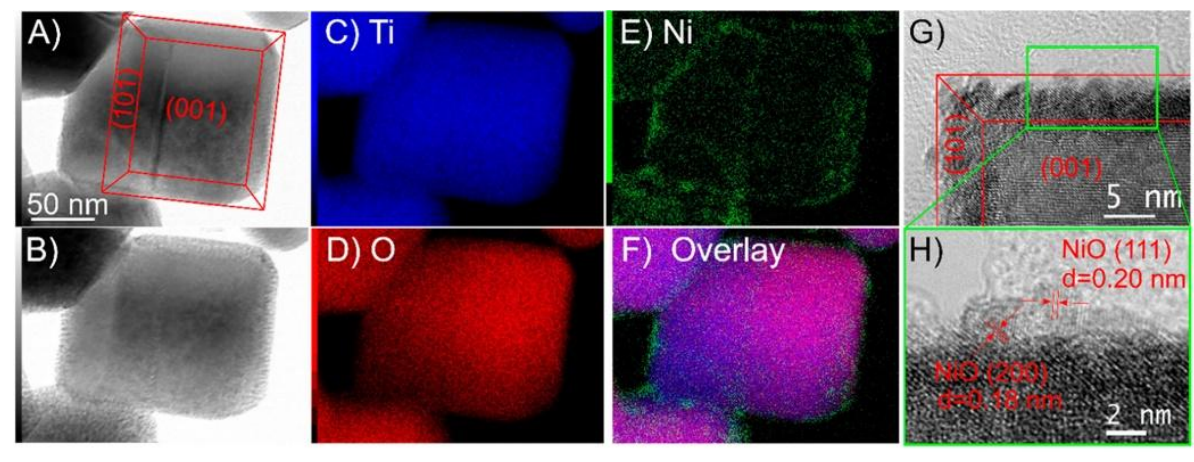

Figure 3. Bright-field STEM images of $10 \mathrm{wt} \% \mathrm{NiO}^{-\mathrm{TiO}_{2}}(\mathrm{~A})$ before and (B) after electron beam irradiation. EDX elemental mapping of (C) Ti, (D) $O,(E) N i$, and $(F)$ overlay. HRTEM images $(G, H)$.

$\mathrm{N}_{2}$ sorption analyses were performed to determine the textural properties of the nanocomposites prepared. Regardless of the nickel oxide content, the sample showed a type II adsorption-desorption isotherm typical of nonporous or macroporous solids with BET specific areas of about (13.4-14.0) $\pm 0.4 \mathrm{~m}^{2} \mathrm{~g}^{-1}$ and total pore volumes of $(0.036-0.044) \pm 0.001 \mathrm{~cm}^{3} \mathrm{~g}^{-1}\left(\right.$ Table $1 \mathrm{and}^{-03}$ Figure S3). These data are consistent with TEM data showing rather well-dispersed nanoparticles with few aggregates. Moreover, depositing up to $10 \mathrm{wt} \% \mathrm{NiO}$ does not change significantly specific surface areas and total pore volumes.

Table 1. Textural Properties ( $S_{\mathrm{BET}}$ and Total Pore Volume) along with Apparent $\left(K_{\mathrm{app}}\right)$ and Normalized Rate Constant $\left(K_{\text {norm }}\right)$ for the Photodecomposition of $\mathrm{MB}$ Using $\mathrm{TiO}_{2}$ and $\mathrm{NiO}-\mathrm{TiO}_{2}$ Photocatalysts

\begin{tabular}{lcccc}
\multicolumn{1}{c}{ sample } & $S_{\text {BET }}\left(\mathrm{m}^{2} \mathrm{~g}^{-1}\right)$ & total pore volume $\left(\mathrm{cm}^{3} \mathrm{~g}^{-1}\right)$ & $K_{\text {app }}\left(\mathrm{min}^{-1}\right)$ & $K_{\text {norm }}\left(\mathrm{mg} \mathrm{m}^{-2} \mathrm{~min}^{-1}\right)$ \\
pure $\mathrm{TiO}_{2}$ & $13.4 \pm 0.4$ & $0.036 \pm 0.001$ & 0.0623 & 4.65 \\
0.1 wt $\% \mathrm{NiO}-\mathrm{TiO}_{2}$ & $13.5 \pm 0.4$ & $0.041 \pm 0.001$ & 0.0961 & 7.11 \\
$0.2 \mathrm{wt} \% \mathrm{NiO}-\mathrm{TiO}_{2}$ & $14.0 \pm 0.4$ & $0.042 \pm 0.001$ & 0.0169 & 1.21 \\
0.5 wt $\% \mathrm{NiO}-\mathrm{TiO}_{2}$ & $14.0 \pm 0.4$ & $0.032 \pm 0.001$ & 0.0096 & 0.72 \\
1 wt $\% \mathrm{NiO}-\mathrm{TiO}_{2}$ & $14.0 \pm 0.4$ & $0.044 \pm 0.001$ & 0.0032 & 0.68 \\
10 wt $\% \mathrm{NiO}-\mathrm{TiO}_{2}$ & $13.7 \pm 0.4$ & $0.042 \pm 0.001$ & 0.24 \\
\hline
\end{tabular}

Optical properties of photocatalysts were investigated by DRS (Figure 4). Heterostructured $\mathrm{NiO}^{-\mathrm{TiO}_{2}}$ samples exhibit visible light absorption of which edges shift toward lower energies with increasing the NiO loading even though the band gap of NiO has been reported to be $3.4-4.3 \mathrm{eV}$, which corresponds to an absorption edge of $288-365 \mathrm{~nm} .(63,64)$ The origin of the visible light absorption exhibited by $\mathrm{NiO}-\mathrm{TiO}_{2}$ nanocomposites can be ascribed to $\mathrm{Ti}-\mathrm{Ni}$ bondings at the $\mathrm{NiO}-\mathrm{TiO}_{2}$ interface or interfacial defect states.(65) DFT calculations revealed that after modification of the $\mathrm{TiO}_{2}$ surface with NiO clusters new states appear above the valence band and just below the conduction band of $\mathrm{TiO}_{2} \cdot(30,66)$ Then, this might result in the narrowed band gap found for $\mathrm{NiO}-\mathrm{TiO}_{2}$ samples and thus the visible light absorption. Nonetheless, it was not possible to determine accurately the optical band gap of the various materials prepared by using the conventional Tauc plot analysis postulating that $\mathrm{TiO}_{2}$ is an indirect semiconductor $(67,68)$ due to the complex composite nature of these materials.(69)

To obtain a deeper understanding of the electronic properties of pure $\mathrm{TiO}_{2}$ and heterostructured $\mathrm{NiO}^{-} \mathrm{TiO}_{2}, \mathrm{XPS}$ measurements were carried out. In addition to carbon, nitrogen, and calcium species which are typical contaminations of ex-situ samples synthesized chemically, emissions from titanium, oxygen, nickel, and indium were detected in the survey spectra (Figure S4). High-resolution scanning for $\mathrm{Ni} 2 \mathrm{p}, \mathrm{O} 1 \mathrm{~s}$, and $\mathrm{Ti} 2 \mathrm{p}$ core level emissions and valence band region emissions are shown in Figure 5. The Fermi level shifts toward a lower energy level from $3.38 \mathrm{eV}$ for pure $\mathrm{TiO}_{2}$ to 3.07, 3.12, 3.15, and 2.20 eV for 0.1, $0.2,1$, and $10 \mathrm{wt} \% \mathrm{NiO}-\mathrm{TiO}_{2}$, respectively (Figure 5D). The $0.5 \mathrm{wt} \% \mathrm{NiO}-\mathrm{TiO}_{2}$ sample does not show any bending, which is evidently related to a smaller amount of $\mathrm{Ni}$ as deposited onto the analyzed area (comparing the $\mathrm{Ni} 2 \mathrm{p}$ vs $\mathrm{Ti} 2 \mathrm{p}$ substrate energies). Core levels of prepared samples follow the shift of the Fermi level position except for the $10 \mathrm{wt} \% \mathrm{NiO}-\mathrm{TiO}_{2}$ sample, the valence band edge of which is affected not only by the Fermi level shift of the $\mathrm{TiO}_{2}$ but also directly by the presence of $\mathrm{O} 2 \mathrm{p}$ orbitals of $\mathrm{NiO}$. The exact analysis of the binding energy values and the possible influence of band bending and possible charging effects are hard to 
discriminate for the samples with different and inhomogeneous distributions of NiO deposits onto nanostructured supports pressed into indium. Therefore, the shifts can only be qualitatively related to the buildup of space charge layers, and details of the contact formation are given from independent layer-by-layer heterojunction formation experiments (see section 3.2). The emission from the $\mathrm{Ti} 2 \mathrm{p}_{3 / 2}$ doublet contains only the $\mathrm{Ti}^{4+}$ line at $459.47 \mathrm{eV}$ without $\mathrm{Ti}^{3+}$ for the pure $\mathrm{TiO}_{2}$ and the peak shifts to the lower binding energy by $140 \mathrm{meV}$ with the presence of NiO (Figure $5 \mathrm{C}$ ). $\mathrm{O}$ 1s spectra show an intense peak assigned to Ti-O bonds accompanying a shoulder at $1.6 \mathrm{eV}$ lower binding energy from the main emission line (Figure 5B). The main line of $\mathrm{O} 1 \mathrm{~s}$ emission also shows an upward bending with $\mathrm{NiO}$ as well as the $\mathrm{Ti} 2 \mathrm{p}_{3 / 2}$ peaks. The presence of $\mathrm{Ni}$ was evidenced by the $\mathrm{Ni} 2 \mathrm{p}_{3 / 2}$ emission line at $856.64 \mathrm{eV}$ with a satellite line at a binding energy higher than that of the main peak by $7.7 \mathrm{eV}$ for the $\mathrm{NiO}^{-\mathrm{TiO}}{ }_{2}$ samples (Figure $5 \mathrm{~A}$ ). Although typical NiO shows a main peak of $\mathrm{Ni} 2 \mathrm{p}_{3 / 2}$ accompanying a shoulder peak at $1.5 \mathrm{eV}$ higher binding energy position which is known as induced by a nonscreening effect, $(70,71)$ the emission of our samples shows broadened shapes, typical also for small thicknesses, from which the main and satellite peaks cannot be distinguished. This broadening might be attributed to the ultrathin layer of $\mathrm{NiO}$ on the anatase particles as the typical intensity pattern of the satellite of $\mathrm{NiO}$ is pronounced when the thickness is less than a few nanometers, resulting in the overlapping of the main and satellite peaks which cannot be clearly identified.

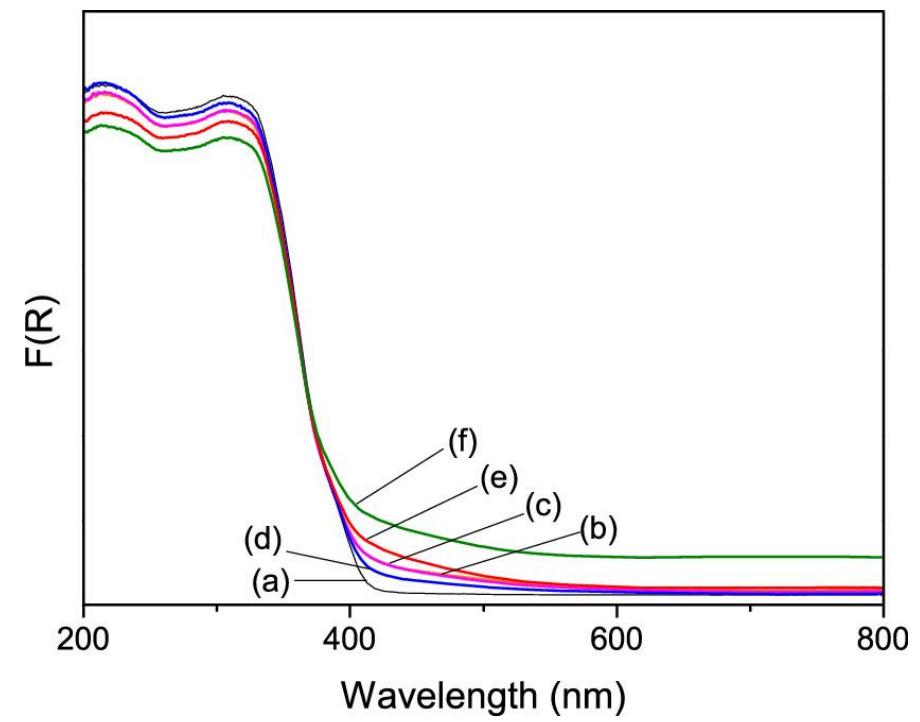

Figure 4. UV-vis diffuse absorption of pure $\mathrm{TiO}_{2}\left(a\right.$, black) and $\mathrm{NiO}-\mathrm{TiO}_{2}$ nanocomposites containing 0.1 (b, orange), 0.2 (c, magenta), 0.5 (d, blue), 1.0 (e, red), and $10 w t \%$ (f, olive) NiO.
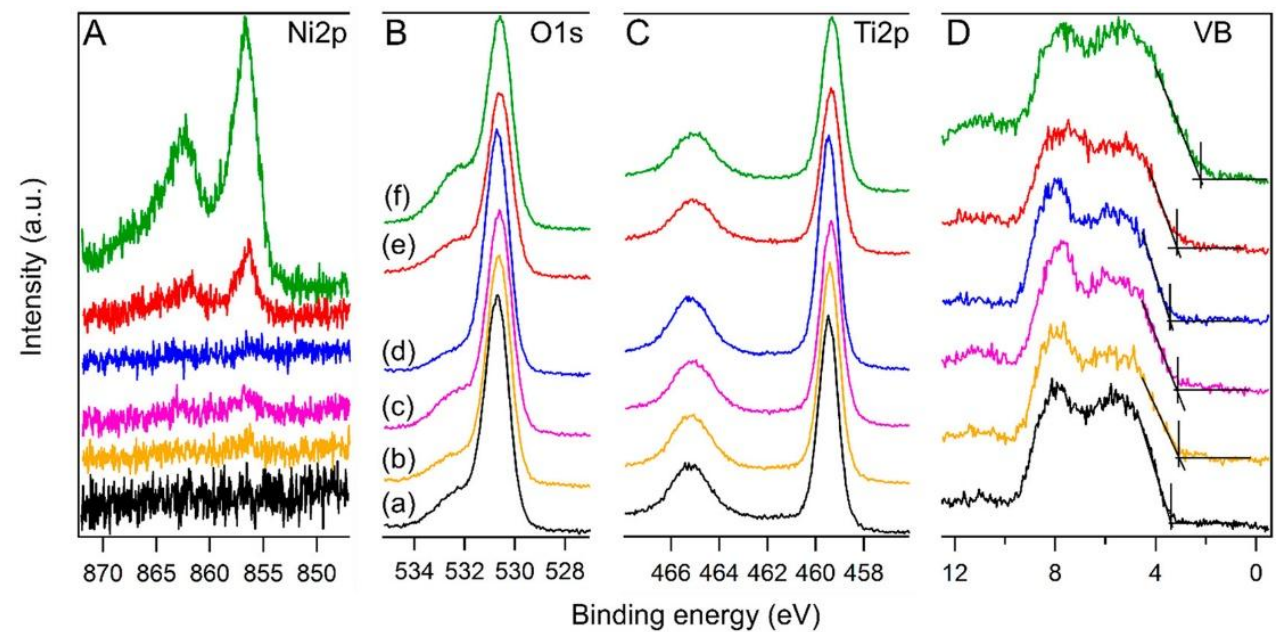

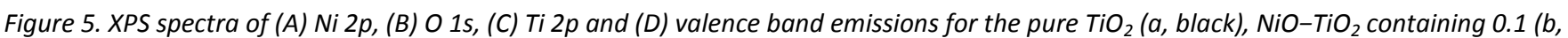
orange), 0.2 (c, magenta), 0.5 (d, blue), 1.0 (e, red), and $10 w t \%$ (f, olive).

\subsection{Interface analysis}


To obtain further insight into the interface properties of the NiO-anatase heterojunction, in-situ interface experiments were performed by XPS and UPS measurements after each deposition step of NiO with increasing thickness onto the stoichiometric anatase (101) and (001) substrates. Figure 6 presents the core level photoelectron spectra recorded during the stepwise deposition for the stoichiometric anatase (101) substrate (for anatase (001) see Figure S5).

A)

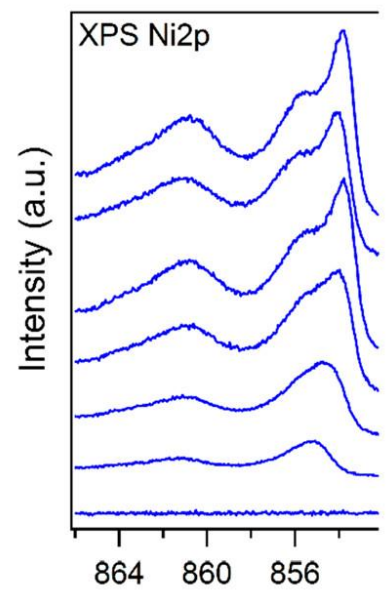

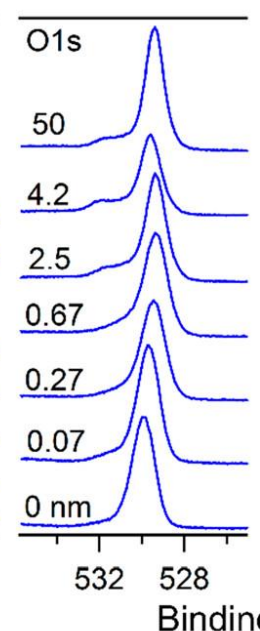

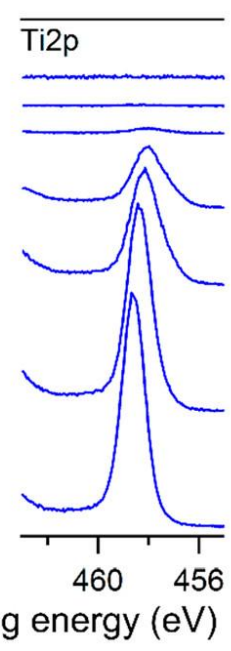

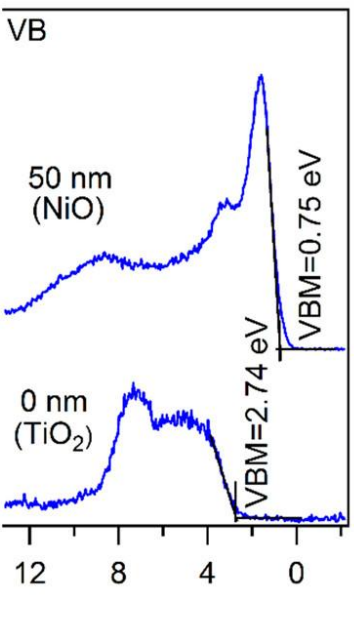

B)

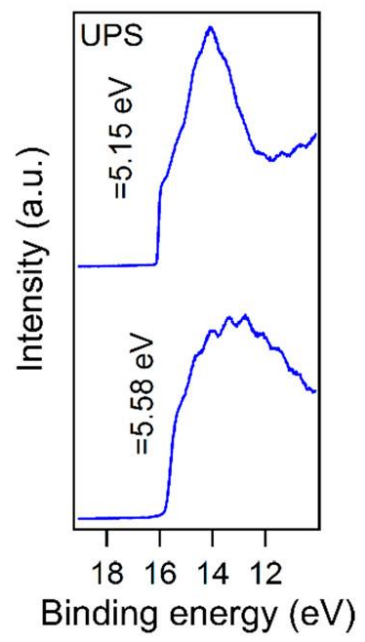

Figure 6. (A) XPS and (B) UPS spectra of the interface experiment performed by stepwise NiO deposition onto the stoichiometric anatase (101) substrate.

The emission of $\mathrm{Ti} 2 \mathrm{p}$ shows the typical doublet peak, but only the $\mathrm{Ti} 2 \mathrm{p}_{3 / 2}$ line is employed to follow the peak shift during the deposition. Complex main line splitting caused by multiplet contributions and satellite structures at higher binding energies cause difficulty in identifying and interpreting $\mathrm{NiO}$ spectra. A binding energy of $853.8 \mathrm{eV}$ is assigned to $\mathrm{Ni} 2 \mathrm{p}_{3 / 2} \mathrm{spectra}$ for $\mathrm{Ni}^{2+}$ of $\mathrm{NiO}_{x}$ which is clearly observed after completing $\mathrm{NiO}$ deposition of thicker than $2.5 \mathrm{~nm}$ which shows the expected two satellite peaks (compared to the $50 \mathrm{~nm}$ thick NiO layer, which is representative of pure NiO undisturbed by the substrate). The spectral feature within the main satellite at a binding energy of around $861 \mathrm{eV}$ indicates that mostly NiO starts to form already from the very beginning of the deposition sequence. The shoulder appearing at a binding energy $1.5 \mathrm{eV}$ higher than the one of the main emission is assigned to a satellite emission of the $\mathrm{Ni}^{2+}$ rather than $\mathrm{Ni}^{3+}$ species. This satellite is a so-called nonlocal screening satellite which appears by a screening process due to oxygen atoms belonging to the octahedral $\mathrm{NiO}_{6}$ coordination.(70) $\mathrm{A}$ broad emission at the low coverage of $\mathrm{NiO}$ is evident and might be associated with an imperfect octahedral structure due to surface effects.(71) With increasing the thickness of the NiO layer, the typical NiO emission signature is detected. The contribution of both the nonlocal and surface effects prevents a determination of the exact binding energy peak position. Thus, the main satellite peak of $\mathrm{Ni} 2 \mathrm{p}_{3 / 2}$ at about $7 \mathrm{eV}$ higher binding energy from the main line of $\mathrm{Ni} 2 \mathrm{p}_{3 / 2}$, which is characteristic for $\mathrm{Ni}^{2+}$, is adopted instead of the main peak to follow the peak shift in the course of NiO deposition.

The $\mathrm{Ti} 2 \mathrm{p}_{3 / 2}$ peak at the beginning of the NiO deposition is rather sharp and symmetric, indicating a mostly stoichiometric surface with dominant $\mathrm{Ti}^{4+}$ oxidation state (Figure 6). However, the asymmetry of the $\mathrm{Ti} 2 \mathrm{p}$ line to lower binding energy evidently increases, suggesting a slight increase of $\mathrm{Ti}^{3+}$ states during NiO deposition. In the $\mathrm{O}$ 1s region, a shoulder peak is observed at higher binding energy than the main peak by $2.3 \mathrm{eV}$ which might be related to the initial formation of the $\mathrm{O}$ poor surface species and possible contributions of adsorbed $\mathrm{OH}^{-}$.

The evolution of the Fermi level $\left(E_{\mathrm{F}}-E_{\mathrm{VBM}}\right)$ of $\mathrm{NiO}$ and anatase substrates obtained by following the core level of Ni $2 p$ satellite and $\mathrm{Ti} 2 \mathrm{p}_{3 / 2}$, respectively, is shown in Figure 7.

The values $E_{\mathrm{F}}-E_{\mathrm{VBM}}$ of pristine stoichiometric anatase substrates and the NiO top layer correspond to the values of $E_{\mathrm{VB}}$ as determined from the valence band spectra. The Fermi level of the uncovered anatase (101) substrate is higher than that of the (001) substrate by $90 \mathrm{meV}$. This might be due to a higher density of oxygen vacancies on the surface and subsurface of the (101) substrate than that of the (001). The Fermi level of both $\mathrm{NiO}$ and anatase shows a parallel shift to lower binding energy, indicating that the band bending occurs only in the anatase substrates and the emission line of Ni $2 p$ just follows the band bending in anatase. The Fermi level shift is attributed to the contact formation between NiO and anatase, forming the $p-n$ junction leading to band bending in contact. It is worth mentioning that the Fermi level of anatase (101) shows a smaller band bending than that of the anatase (001) by $210 \mathrm{meV}$. This is attributed to stable oxygen subsurface oxygen vacancies of the anatase (101) which would pin the Fermi level at $2.16 \mathrm{eV}$. 


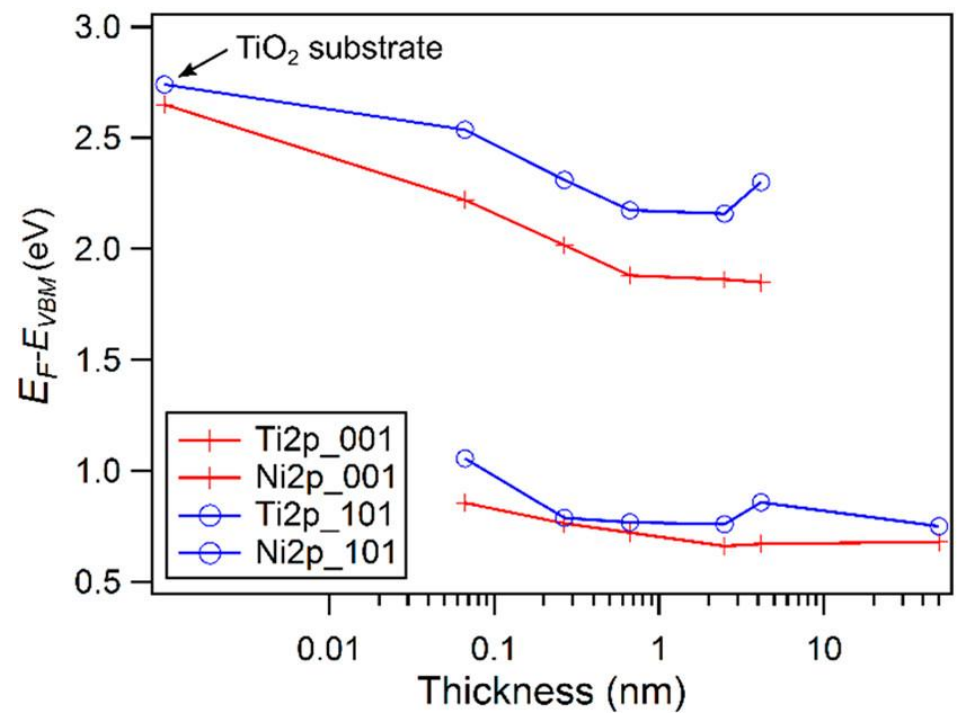

Figure 7. Fermi level ( $\left.E_{F}-E_{V B M}\right)$ measured during stepwise deposition of NiO onto the stoichiometric anatase (101) substrate.

The work function of the uncovered anatase substrates and top layers of deposited NiO was derived from the binding energies of the secondary electron edge $E_{\mathrm{SE}}$ according to $\Phi=h v-E_{\mathrm{SE}}$. The work function of the stoichiometric anatase (101) and (001) substrates is 5.58 and $5.63 \mathrm{eV}$, respectively. The work function of $\mathrm{NiO}$ on the anatase (101) and (001) substrates is 5.15 and 5.17 $\mathrm{eV}$, respectively. No noticeable difference in work function of $\mathrm{NiO}$ indicates that $\mathrm{NiO}$ on both orientations of anatase would possess similar stoichiometry without being influenced by different surface coordination of these orientations.

Finally, the band alignments at the interface of NiO-anatase (101) and NiO-anatase (001) as experimentally established by using the above data are shown in Figure 8 and Figure 6.

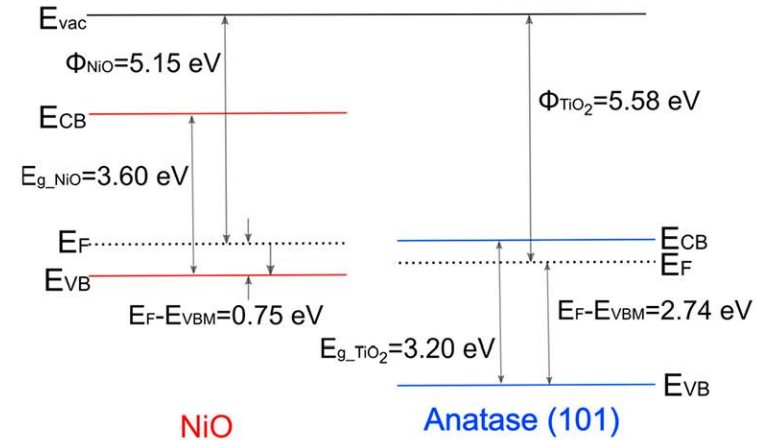

Before contact

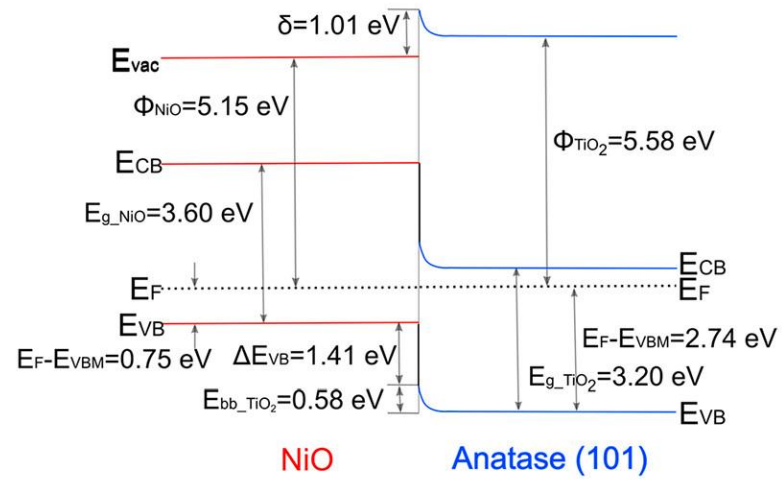

After contact

Figure 8. Band energy diagrams of $p-\mathrm{NiO}-n-\mathrm{TiO}_{2}$ anatase (101) before and after contact as determined from the experimental data. The important values are given in the figures.

As is evident from these diagrams, the band bending at the interface of $\mathrm{p}$-doped $\mathrm{NiO}$ and $\mathrm{n}$-doped $\mathrm{TiO}_{2}$ for the anatase $(001)$ is larger than that for the anatase (101) by $210 \mathrm{meV}$. In p-NiO the Fermi level is pinned by a high concentration of defect states $\left(\mathrm{Ni}^{3+}\right.$ related states) in the bulk of the material as there is no additional band bending observed in the NiO layers. The pinning level is found at a value of $E_{\mathrm{F}}-E_{\mathrm{VBM}}$ between 0.68 and $0.75 \mathrm{eV}$. Strong band bending within the $\mathrm{TiO}_{2}$ substrates is achieved by the deposition of thin $\mathrm{NiO}$ layers of thicknesses larger than $1 \mathrm{~nm}$, which would contribute to charge carriers separation in nanoparticle photocatalyst systems. The fact that the space charge layer observed for the NiO particles on the $\{101\}$ facets of $\mathrm{TiO}_{2}$ is considerably smaller can be understood based on the different surface properties of the two facets which have already been discussed in details in a previous paper. For small particles the space charge layer is inhomogeneous, and only a small fraction is detected for the rare areas. Second, for small dimensions of the $\mathrm{NiO}$ overlayer onto $\mathrm{TiO}_{2}$ substrates the complete space charge layer may not be found due to exhaustion of charge carriers.

\subsection{Photocatalytic properties}


To examine the photocatalytic activity of the pure $\mathrm{TiO}_{2}$ and $\mathrm{NiO}-\mathrm{TiO}_{2}$ nanomaterials, the photodecomposition of methylene blue (MB) was performed under UV illumination.

Figure 9A shows stepwise attenuation of the characteristic absorption peaks of $\mathrm{MB}$ during its photocatalytic decomposition in the presence of $0.1 \mathrm{wt} \% \mathrm{NiO}_{-} \mathrm{TiO}_{2}$. A slight hypsochromic shift of the maximum absorption wavelength, from 664 to $650 \mathrm{~nm}$ after 40 min of irradiation, was observed, which suggests the demethylation of methylene blue yielding Azur B and Azur A chromophore intermediates.(72,73) Finally, MB was completely decolorized within 60 min under UV-light irradiation, evidencing the high photocatalytic efficiency of the $0.1 \mathrm{wt} \% \mathrm{NiO}_{-} \mathrm{TiO}_{2}$ heterostructure. The photocatalytic activities of pure $\mathrm{TiO}_{2}$ and $\mathrm{NiO}-$ $\mathrm{TiO}_{2}$ photocatalysts with various $\mathrm{NiO}$ contents are shown in Figure 9B. For quantitative evaluation of the reaction kinetics of the $\mathrm{MB}$ degradation, a pseudo-first-order model expressed as $\ln \left(C / C_{0}\right)=-K_{\text {app }} t$ was applied. Here, $C_{0}$ and $C$ correspond to the concentration of $\mathrm{MB}$ in solution at time 0 and $t$, respectively, and $K_{\text {app }}$ stands for the apparent first-order rate constant for $\mathrm{MB}$ degradation. $K_{\text {app }}$ can be obtained from the slope of the curve $\ln \left(C / C_{0}\right)$ vs $t$. Regardless of the photocatalyst used, the MB degradation follows the pseudo-first-order reaction kinetics at the beginning of the process. Furthermore, to avoid the influence of the surface area of the photocatalysts on the rate constant, the normalized rate constant $\left(K_{\text {norm }}\right)$ defined as $K_{\text {norm }}=K_{\mathrm{app}} / S_{\mathrm{BET}}$ was calculated as summarized in Table 1 . The $0.1 \mathrm{wt} \% \mathrm{NiO}_{-} \mathrm{TiO}_{2}$ photocatalyst shows the highest activity, and its $K_{\text {norm }}$ is higher than that of the pure $\mathrm{TiO}_{2}$ by $50 \%$. This result confirms the key role of the combination of $\mathrm{NiO}$ with $\mathrm{TiO}_{2}$ for enhancing the photocatalytic activities which can be attributed to the enhanced charge separation due to the electric field at the interface of the $\mathrm{p}-\mathrm{n}$ junction between $\mathrm{NiO}$ and $\mathrm{TiO}_{2}$ as described below.
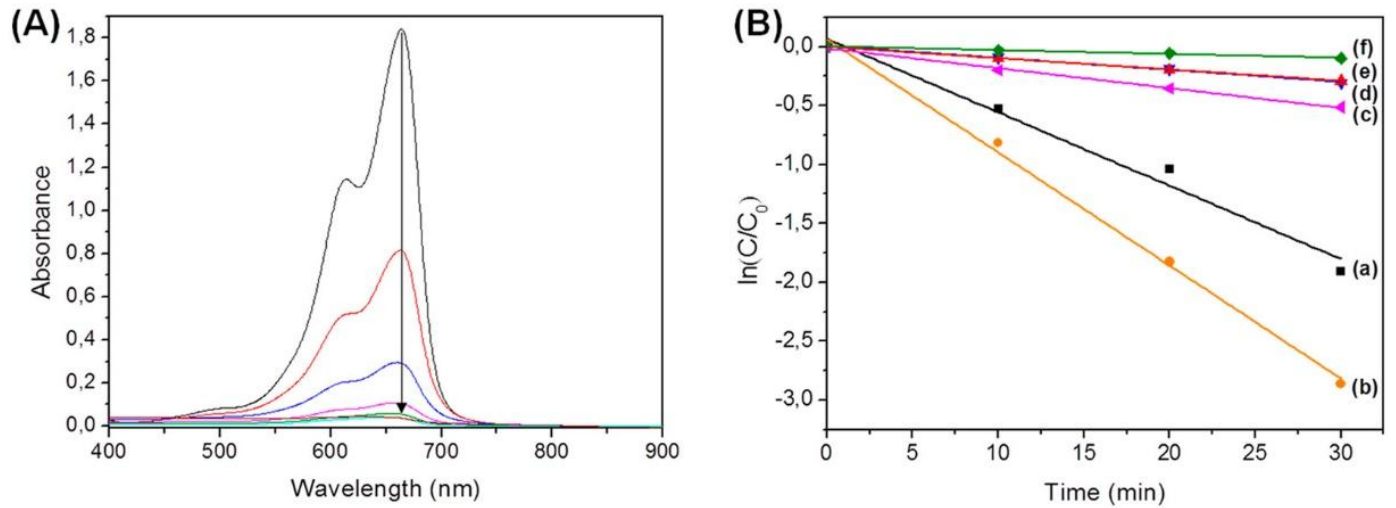

Figure 9. (A) Absorbance change in the visible range of methylene blue solution after various illumination times for 0.1 wt $\% \mathrm{NiO}^{-\mathrm{TiO}} \mathrm{Z}_{2}$ : before irradiation (black), $10 \mathrm{~min}$ (red), $20 \mathrm{~min}$ (blue), $30 \mathrm{~min}$ (magenta), $40 \mathrm{~min}$ (olive), $50 \mathrm{~min}$ (cyan), and $60 \mathrm{~min}$ (purple). (B) Pseudo-first-order kinetics expressed by $\ln \left(C / C_{0}\right)$ vs irradiation time tof the degradation of $\mathrm{MB}$ for the pure $\mathrm{TiO}_{2}$ (a, black), NiO-TiO ${ }_{2}$ containing 0.1 (b, orange), 0.2 (c, magenta), 0.5 (d, blue), 1.0 (e, red), and $10 w t \%$ (f, olive) NiO.

\subsection{Mechanistic consideration}

According to literature data, the following mechanism can be proposed.(37) After light absorption by the photocatalyst, the photoexcited electron and holes are transferred to $\mathrm{TiO}_{2}$ and $\mathrm{NiO}$, respectively, at the $\mathrm{p}-\mathrm{n}$ junction. The electrons transferred to $\mathrm{TiO}_{2}$ take part in the reduction of dissolved oxygen, forming a superoxide radical $\mathrm{O}_{2}{ }^{--}$. The $\mathrm{O}_{2}{ }^{\circ-}$ radicals react with $\mathrm{H}_{2} \mathrm{O}$ to produce hydroxyl radicals $\mathrm{OH}^{\bullet}$ which are strong oxidizing agents leading to dye decomposition. At the same time, the holes transferred to $\mathrm{NiO}$ directly react with surface adsorbed dyes leading to the dye degradation and also oxidize the surface hydroxyl groups or physisorbed $\mathrm{H}_{2} \mathrm{O}$ forming $\mathrm{OH}^{*}$. Thus, the charge carriers, the lifetime of which is prolonged by spatial charge separation at the $\mathrm{p}-\mathrm{n}$ junction, would acquire a higher probability to encounter reactants producing radicals in the solution and then account for the high photocatalytic activities.

To obtain a deeper understanding of the photodecomposition mechanism in the presence of $\mathrm{TiO}_{2}$ and $\mathrm{NiO}^{-} \mathrm{TiO}_{2}$ nanomaterials, potassium iodide (KI), isopropyl alcohol (IPA), and 1,4-benzoquinone (BQ) were employed as hole $\left(\mathrm{h}^{+}\right)$, hydroxyl radical $\left(\mathrm{OH}^{\bullet}\right)$, and superoxide radical $\left({ }^{\circ} \mathrm{O}^{2-}\right)$ scavengers, respectively, for $\mathrm{MB}$ degradation. The corresponding kinetic rate constants for $\mathrm{MB}$ decomposition normalized by that without scavengers are reported in Figure 10. 


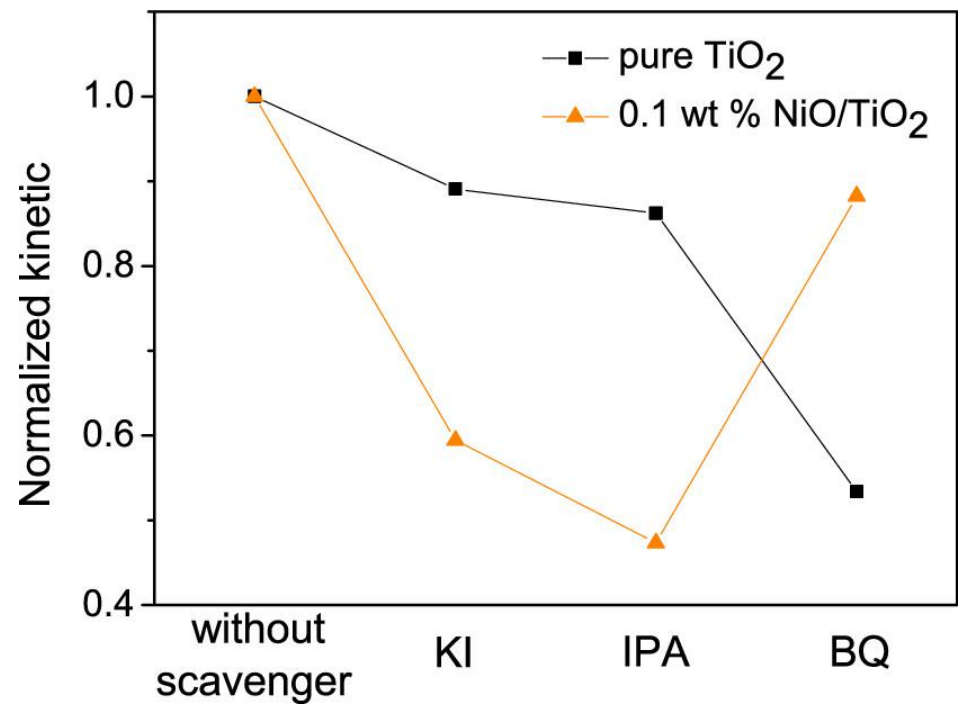

Figure 10. Kinetic rate constants for $\mathrm{MB}$ decomposition normalized by that without scavengers for pure $\mathrm{TiO}_{2}$ (black) and 0.1 wt $\% \mathrm{NiO}^{-\mathrm{TiO}}{ }_{2}$ (orange) without scavengers or in the presence of potassium iodide (KI), isopropanol (IPA), and 1,4-benzoquinone (BQ).

First of all, it can be clearly seen that the species involved in the photocatalytic decomposition of $M B$ depend on the photocatalyst used. Thus, for pure $\mathrm{TiO}_{2}$ photocatalyst, the degradation efficiency of $\mathrm{MB}$ decreased obviously in the presence of $\mathrm{BQ}$ while it was almost not affected by the addition of $\mathrm{KI}$ and IPA. This means that ${ }^{\circ} \mathrm{O}^{2-}$ radicals, which are created via

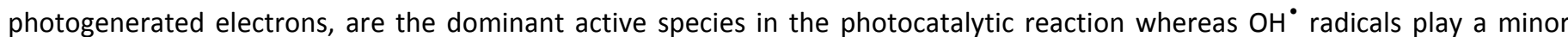
role. The $\mathrm{TiO}_{2}$ crystals used in this study have an averaged aspect ratio $(B / A),(74)$ which is defined by the ratio of the short $B$ and long $A$ sides of the top-truncated bipyramidal crystal, of around 0.7.(31) The value corresponds to $72 \%$ exposure of the $\{101\}$ facet, and thus it is expected that electrons, which are supposed to be accumulated onto the majority (101) facet, are relevant in photocatalysis for the pure $\mathrm{TiO}_{2}$. By contrast, photocatalytic activities of $0.1 \mathrm{wt} \% \mathrm{NiO}-\mathrm{TiO}_{2}$ nanomaterials were decreased by addition of $\mathrm{KI}$ and IPA, whereas $\mathrm{BQ}$ has almost no effect. Although both holes and electrons would contribute to $\mathrm{create}^{\circ} \mathrm{OH}^{\bullet}$ and oxidize the $\mathrm{MB}, \mathrm{BQ}$ as a scavenger of ${ }^{\circ} \mathrm{O}^{2-}$ created by only electrons did not affect much the photocatalytic activities. This reveals that holes mainly dictate the photocatalytic $\mathrm{MB}$ decomposition on the $0.1 \mathrm{wt} \% \mathrm{NiO}_{-} \mathrm{TiO}_{2}$ photocatalysts. Despite the $\mathrm{TiO}_{2}$ crystals used mainly expose $\{101\}$ facets acting as electron sinks, NiO deposited onto the $\{101\}$ facets would not only effectively collect holes at the $\mathrm{p}-\mathrm{n} \mathrm{NiO}-\mathrm{TiO}_{2}\{101\}$ junction but also catalyze the reaction by lowering the activation energy, and therefore holes can be competitive rather than electrons. However, simultaneous consumption of both electrons and holes is required to achieve optimal photocatalytic performances since the accumulation of electrons or holes might result in a higher recombination rate. The deposition of more than $0.2 \mathrm{wt} \% \mathrm{NiO}_{\text {onto }} \mathrm{TiO}_{2}$ might cover the naked (101) anatase surface more than enough and generate unreacted electrons. These charge carriers will accumulate and trigger a higher possibility of the recombination. Thus, for this $\mathrm{NiO}-\mathrm{TiO}_{2}(101)$ system, the $0.1 \mathrm{wt} \% \mathrm{NiO}-\mathrm{TiO}_{2}$ photocatalyst showed the best photocatalytic activity.

\section{Conclusion}

The selective photodeposition of $\mathrm{NiO}$ nanoparticles onto the $\{101\}$ facets of oriented $\mathrm{TiO}_{2}$ anatase nanocrystals coexposed with $\{001\}$ and $\{101\}$ facets was achieved for the first time to yield efficient $\mathrm{NiO}$-anatase $\mathrm{TiO}_{2}$ photocatalysts. The $\mathrm{NiO}-\mathrm{TiO}_{2}$ heterostructure nanoparticles showed light absorption properties shifted toward visible light region compared to those of pure $\mathrm{TiO}_{2}$. Furthermore, interface model experiments of $\mathrm{NiO}$ deposited onto $\mathrm{TiO}_{2}$ substrates were conducted and compared to $\mathrm{NiO}-$ $\mathrm{TiO}_{2}$ faceted nanostructures to experimentally determine the energy band alignment diagrams of the $\mathrm{NiO}^{-o r i e n t e d} \mathrm{TiO}_{2}$ heterostructure. The $0.58 \mathrm{eV}$ shifts of core levels toward lower binding energy were assigned to an upward band bending in $\mathrm{TiO}_{2}$ anatase (101) substrates which is expected to favor electron-hole charge separation at the interface. The difference of band bending of only smaller than $0.3 \mathrm{eV}$ is related to size effects. The $0.1 \mathrm{wt} \% \mathrm{NiO}-\mathrm{TiO}_{2}$ actually showed $50 \%$ higher photocatalytic activity than the pure $\mathrm{TiO}_{2}$ for $\mathrm{MB}$ photodegradation due to effective charge separation by the internal electric field formed at the $\mathrm{p}-\mathrm{n} \mathrm{NiO}-\mathrm{TiO}_{2}$ heterojunction. Finally, further mechanistic studies performed by using carrier and radical scavengers revealed that holes dominantly dictate the photocatalytic reactions for $\mathrm{NiO}_{-} \mathrm{TiO}_{2}$ nanocomposites whereas electrons mainly participate in the photocatalytic reactions rather than holes for the pure $\mathrm{TiO}_{2}$. These results underline the key role of selective deposition of $\mathrm{NiO}$ onto anatase $\mathrm{TiO}_{2}$ nanocrystals on photocatalytic processes. This work will inspire optimal designs of heterostructure 
systems for the efficient photocatalytic process by combining an appropriate choice of cocatalysts and selective deposition onto the specific facet of supported photocatalyst crystals.

The Supporting Information is available free of charge on the ACS Publications website at DOI: 10.1021/acsanm.9b00729.

Authors : Shun Kashiwaya - http://orcid.org/0000-0002-3164-8403

Jérôme Majimel - ICMCB UMR 5026, CNRS, Univ. Bordeaux INP, F-33600 Talence, France

Andreas Klein - http://orcid.org/0000-0001-7463-1495

Wolfram Jaegermann - Fachbereich Material- und Geowissenshaften, Technische Universität Darmstadt, Petersenstr. 23, 64287 Darmstadt,

Germany

Notes : The authors declare no competing financial interest.

Acknowlegments : Prof. Ohtani is warmly acknowledged for providing the single crystalline $\mathrm{TiO}_{2}$ anatase particles coexposed with $\{001\}$ and $\{101\}$ facets. Dr. Marie-Anne Dourges (ISM) and Mrs Muriel Alrivie (LCTS) are acknowledged for their help in collecting the $\mathrm{N}_{2}$ sorption and SEM data. This work was supported by the European Commission ((S. K. Fellowship, Erasmus Mundus Doctoral School IDS-FunMat, Grant Agreement EMJD FPA 2010/0004 SGA 2014-0966) and the “Université Franco-allemande" (German-French Doctoral College in Functional Materials: Contract CDFA 02-15 (2018-2021)). We thank the PLACAMAT structure for its electron microscopy facilities and EMMI (European Multifunctional Material Institute).

\section{References}

1. Zhu, K.; Neale, N. R.; Miedaner, A.; Frank, A. J. Enhanced Charge-Collection Efficiencies and Light Scattering in Dye-Sensitized Solar Cells Using Oriented $\mathrm{TiO}_{2}$ Nanotubes Arrays. Nano Lett. 2007, 7, 69- 74, DOI: 10.1021/nl062000o

2. Liu, B.; Aydil, E. S. Growth of Oriented Single-Crystalline Rutile $\mathrm{TiO}_{2}$ Nanorods on Transparent Conducting Substrates for DyeSensitized Solar Cells. J. Am. Chem. Soc. 2009, 131, 3985-90, DOI: 10.1021/ja8078972

3. Yun, J.-H.; Wang, L.; Amal, R.; Ng, Y. H. One-Dimensional $\mathrm{TiO}_{2}$ Nanostructured Photoanodes: From Dye-Sensitized Solar Cells to Perovskite Solar Cells. Energies 2016, 9, 1030, DOI: 10.3390/en9121030

4. Wang, D.; Choi, D.; Li, J.; Yang, Z.; Nie, Z.; Kou, R.; Hu, D.; Wang, C.; Saraf, L. V.; Zhang, J.; Aksay, I. A.; Liu, J. Self-Assembled TiO ${ }_{2}^{-}$ Graphene Hybrid Nanostructures for Enhanced Li-Ion Insertion. ACS Nano 2009, 3, 907-14, DOI: 10.1021/nn900150y

5. Yang, G.; Wang, L.; Peng, S.; Wang, J.; Ji, D.; Yan, W.; Ramakrishna, S. In Situ Fabrication of Hierarchically Branched $\mathrm{TiO}_{2}$ Nanostructures: Enhanced Performance in Photocatalytic $\mathrm{H}_{2}$ Evolution and Li-Ion Batteries. Small 2017, 13, 1702357, DOI: 10.1002/smll.201702357

6. Fujishima, A.; Honda, K. Electrochemical Photolysis of Water at a Semiconductor Electrode. Nature 1972, 238, 37-38, DOI: $10.1038 / 238037 \mathrm{a0}$

7. Linsebigler, A. L.; Lu, G.; Yates, J. T. Photocatalysis on $\mathrm{TiO}_{2}$ Surfaces: Principles, Mechanisms, and Selected Results. Chem. Rev. 1995, 95, 735- 58, DOI: 10.1021/cr00035a013

8. Walter, M. G.; Warren, E. L.; McKone, J. R.; Boettcher, S. W.; Mi, Q.; Santori, E. A.; Lewis, N. S. Solar Water Splitting Cells. Chem. Rev. 2010, 110, 6446-73, DOI: 10.1021/cr1002326

9. Dhakshinamoorthy, A.; Navalon, S.; Corma, A.; Garcia, H. Photocatalytic $\mathrm{CO}_{2}$ reduction by $\mathrm{TiO}_{2}$ and related titanium containing solids. Energy Environ. Sci. 2012, 5, 9217- 23, DOI: 10.1039/c2ee21948d

10. Kamat, P. V. Manipulation of Charge Transfer across Semiconductor Interface. A Criterion That Cannot Be Ignored in Photocatalyst Design. J. Phys. Chem. Lett. 2012, 3, 663- 72, DOI: 10.1021/jz201629p

11. Takai, A.; Kamat, P. V. Capture, Store, and Discharge. Shuttling Photogenerated Electrons across $\mathrm{TiO}_{2}$-Silver Interface. ACS Nano 2011, 5, 7369-76, DOI: 10.1021/nn202294b

12. Yang, J.; Wang, D.; Han, H.; Li, C. Roles of Cocatalysts in Photocatalysis and Photoelectrocatalysis. Acc. Chem. Res. 2013, 46, 1900- 9 , DOI: 10.1021/ar300227e

13. Li, Y.; Li, T.; Tian, J.; Wang, X.; Cui, H. TiO 2 Nanobelts Decorated with $\ln _{2} \mathrm{~S}_{3}$ Nanoparticles as Photocatalysts with Enhanced Full-SolarSpectrum (UV-vis-NIR) Photocatalytic Activity toward the Degradation of Tetracycline. Part. Part. Syst. Charact. 2017, 34, 1700127, DOI: 10.1002/ppsc.201700127

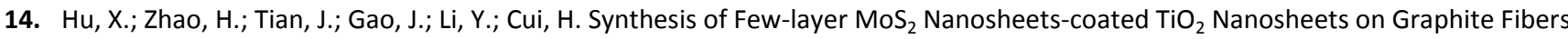
for Enhanced Photocatalytic Properties. Sol. Energy Mater. Sol. Cells 2017, 172, 108- 16, DOI: 10.1016/j.solmat.2017.07.027

15. Li, Y.; Deng, X.; Tian, J.; Liang, Z.; Cui, H. $\mathrm{Ti}_{3} \mathrm{C}_{2}$ MXene-derived $\mathrm{Ti}_{3} \mathrm{C}_{2} / \mathrm{TiO}_{2}$ Nanoflowers for Noble-metal-free Photocatalytic Overall Water Splitting. Appl. Mater. Today 2018, 13, 217-27, DOI: 10.1016/j.apmt.2018.09.004

16. Wei, N.; Wu, Y.; Wang, M.; Sun, W.; Li, Z.; Ding, L.; Cui, H. Construction of Noble-metal-free $\mathrm{TiO}_{2} \mathrm{Nanobelt} / Z n \mathrm{In}_{2} \mathrm{~S}_{4} \mathrm{Nanasheet}$ Heterojunction Nanocomposite for Highly Efficient Photocatalytic Hydrogen Evolution. Nanotechnology 2019, 30, 045701, DOI: 10.1088/1361-6528/aaecc6

17. Trasatti, S. Work Function, Electronegativity, and Electrochemical Behaviour of Metals. J. Electroanal. Chem. Interfacial Electrochem. 1972, 39, 163-84, DOI: 10.1016/S0022-0728(72)80485-6 
18. Maeda, K.; Domen, K. Photocatalytic Water Splitting: Recent Progress and Future Challenges. J. Phys. Chem. Lett. 2010, 1, 2655-61, DOI: $10.1021 / \mathrm{jz} 1007966$

19. Ohno, T.; Sarukawa, K.; Matsumura, M. Crystal Faces of Rutile and Anatase $\mathrm{TiO}_{2}$ Particles and Their Roles in Photocatalytic Reactions. New J. Chem. 2002, 26, 1167- 70, DOI: 10.1039/b202140d

20. Tachikawa, T.; Yamashita, S.; Majima, T. Evidence for Crystal-Face-Dependent $\mathrm{TiO}_{2}$ Photocatalysis from Single-Molecule Imaging and Kinetic Analysis. J. Am. Chem. Soc. 2011, 133, 7197-204, DOI: 10.1021/ja201415j

21. Liu, G.; Yu, J. C.; Lu, G. Q.; Cheng, H. M. Crystal Facet Engineering of Semiconductor Photocatalysts: Motivations, Advances and Unique Properties. Chem. Commun. 2011, 47, 6763-83, DOI: 10.1039/c1cc10665a

22. D’Arienzo, M.; Carbajo, J.; Bahamonde, A.; Crippa, M.; Polizzi, S.; Scotti, R.; Wahba, L.; Morazzoni, F. Photogenerated Defects in Shape-Controlled $\mathrm{TiO}_{2}$ Anatase Nanocrystals: A Probe to Evaluate the Role of Crystal Facets in Photocatalytic Processes. J. Am. Chem. Soc. 2011, 133, 17652-61, DOI: 10.1021/ja204838s

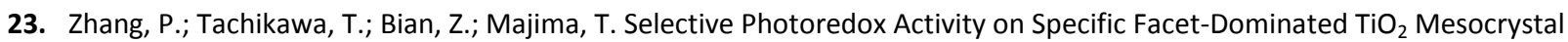
Superstructures Incubated with Directed Nanocrystals. Appl. Catal., B 2015, 176-177, 678- 86, DOI: 10.1016/j.apcatb.2015.04.053

24. Wang, X.; Li, T.; Yu, R.; Yu, H.; Yu, J. Highly Efficient $\mathrm{TiO}_{2}$ Single-crystal photocatalyst with Spatially Separated Ag and $\mathrm{F}^{-}$bi-Cocatalysts: Orientation Transfer of Photogenerated Charges and Their Rapid Interfacial Reaction. J. Mater. Chem. A 2016, 4, 8682-89, DOI: 10.1039/C6TA02039A

25. Zhang, J.; Zhang, L.; Shi, Y.; Xu, G.; Zhang, E.; Wang, H.; Kong, Z.; Xi, J.; Ji, Z. Anatase $\mathrm{TiO}_{2}$ Nanosheets with Coexposed $\{101\}$ and $\{001\}$ Facets Coupled with Ultrathin $\mathrm{SnS}_{2}$ Nanosheets as a Face-to-face $n-p-n$ Dual Heterojunction Photocatalyst for Enhancing Photocatalytic Activity. Appl. Surf. Sci. 2017, 420, 839- 48, DOI: 10.1016/j.apsusc.2017.05.160

26. Sun, C.; Liu, L.-M.; Selloni, A.; Lu, G. Q.; Smith, S. C. Titania-Water Interactions: A Review of Theoretical Studies. J. Mater. Chem. 2010, 20, 10319-34, DOI: 10.1039/c0jm01491e

27. Gong, X. Q.; Selloni, A. Reactivity of Anatase TiO(2) Nanoparticles: The Role of the Minority (001) Surface. J. Phys. Chem. B 2005, 109, 19560- 2, DOI: 10.1021/jp055311g

28. Yang, H. G.; Sun, C. H.; Qiao, S. Z.; Zou, J.; Liu, G.; Smith, S. C.; Cheng, H. M.; Lu, G. Q. Anatase TiO 2 Single Crystals with a Large Percentage of Reactive Facets. Nature 2008, 453, 638-41, DOI: 10.1038/nature06964

29. Chen, W.; Kuang, Q.; Wang, Q.; Xie, Z. Engineering a High Energy Surface of Anatase $\mathrm{TiO}_{2}$ Crystals Towards Enhanced Performance for Energy Conversion and Environmental Applications. RSC Adv. 2015, 5, 20396- 409, DOI: 10.1039/C5RA00344J

30. Murakami, N.; Kurihara, Y.; Tsubota, T.; Ohno, T. Shape-Controlled Anatase Titanium(IV) Oxide Particles Prepared by Hydrothermal Treatment of Peroxo Titanic Acid in the Presence of Polyvinyl Alcohol. J. Phys. Chem. C 2009, 113, 3062-69, DOI: 10.1021/jp809104t

31. Amano, F.; Prieto-Mahaney, O.-O.; Terada, Y.; Yasumoto, T.; Shibayama, T.; Ohtani, B. Decahedral Single-Crystalline Particles of Anatase Titanium(IV) Oxide with High Photocatalytic Activity. Chem. Mater. 2009, 21, 2601- 03, DOI: 10.1021/cm9004344

32. Roy, N.; Sohn, Y.; Pradhan, D. Synergy of Low-Energy $\{101\}$ and High-Energy $\{001\}$ TiO(2) Crystal Facets for Enhanced Photocatalysis. ACS Nano 2013, 7, 2532-40, DOI: 10.1021/nn305877v

33. Yu, J.; Low, J.; Xiao, W.; Zhou, P.; Jaroniec, M. Enhanced Photocatalytic Co(2)-Reduction Activity of Anatase TiO(2) by Coexposed $\{001\}$ and $\{101\}$ Facets. J. Am. Chem. Soc. 2014, 136, 8839-42, DOI: 10.1021/ja5044787

34. Kashiwaya, S.; Toupance, T.; Klein, A.; Jaegermann, W. Fermil Level Positions and Induced Band Bending at Single Crystalline Anatase (101) and (001) Surfaces: Origin of the Enhanced Photocatalytic Activity of Facet Engineered Crystals. Adv. Ener. Mater. 2018, 8 , 1802195, DOI: 10.1002/aenm.201802195

35. Ku, Y.; Lin, C.-N.; Hou, W.-M. Characterization of Coupled $\mathrm{NiO} / \mathrm{TiO}_{2}$ Photocatalyst for the Photocatalytic Reduction of $\mathrm{Cr}(\mathrm{VI})$ in Aqueous Solution. J. Mol. Catal. A: Chem. 2011, 349, 20-27, DOI: 10.1016/j.molcata.2011.08.006

36. Iwaszuk, A.; Nolan, M.; Jin, Q.; Fujishima, M.; Tada, H. Origin of the Visible-Light Response of Nickel(II) Oxide Cluster Surface Modified Titanium(IV) Dioxide. J. Phys. Chem. C 2013, 117, 2709- 18, DOI: 10.1021/jp306793r

37. Wang, M.; Hu, Y.; Han, J.; Guo, R.; Xiong, H.; Yin, Y. $\mathrm{TiO}_{2} / \mathrm{NiO}$ Hybrid Shells: $\mathrm{p}$-n Junction Photocatalysts with Enhanced Activity under Visible-light. J. Mater. Chem. A 2015, 3, 20727-35, DOI: 10.1039/C5TA05839B

38. Pandi, $\mathrm{P}$.; Gopinathan, C. Synthesis and Characterization of $\mathrm{TiO}_{2}-\mathrm{NiO}$ and $\mathrm{TiO}_{2}-\mathrm{WO}_{3}$ Nanocomposites. J. Mater. Sci.: Mater. Electron. 2017, 28, 5222- 34

39. Wahyuningsih, S; Ramelan, A H; Purwanti, P D; Munawaroh, H; Ichsan, S; Kristiawan, Y R The Influence of $\mathrm{NiO}^{-1 d d i t i o n ~ i n ~} \mathrm{TiO}_{2}$ Structure and Its Photoactivity. IOP Conf. Ser.: Mater. Sci. Eng. 2018, 333, 012032, DOI: 10.1088/1757-899X/333/1/012032

40. Kashiwaya, S.; Aymonier, C.; Majimel, J.; Olivier, C.; Klein, A.; Jaegermann, W.; Toupance, T. Supercritical $\mathrm{CO}_{2}$-assisted Deposition of $\mathrm{NiO}$ on (101)-anatase- $\mathrm{TiO}_{2}$ for Efficient Facet Engineered Photocatalysts. New J. Chem. 2018, 42, 18649-58, DOI: $10.1039 /$ C8NJ04292F

41. Liu, J.; Li, Y.; Ke, J.; Wang, S.; Wang, L.; Xiao, H. Black NiO-TiO 2 nanorods for solar photocatalysis: Recognition of electronic structure and reaction mechanism. Appl. Catal., B 2018, 224, 705-14, DOI: 10.1016/j.apcatb.2017.11.028

42. Fujita, S.-i.; Kawamori, H.; Honda, D.; Yoshida, H.; Arai, M. Photocatalytic Hydrogen Production from Aqueous Glycerol Solution Using $\mathrm{NiO} / \mathrm{TiO}_{2}$ Catalysts: Effects of Preparation and Reaction Conditions. Appl. Catal., B 2016, 181, 818-24, DOI: 10.1016/j.apcatb.2015.08.048

43. Uddin, M. T.; Nicolas, Y.; Olivier, C.; Jaegermann, W.; Rockstroh, N.; Junge, H.; Toupance, T. Band Alignment Investigations of Heterostructure $\mathrm{NiO} / \mathrm{TiO}_{2}$ Nanomaterials Used as Efficient Heterojunction Earth-Abundant Metal Oxide Photocatalysts for Hydrogen Production. Phys. Chem. Chem. Phys. 2017, 19, 19279-88, DOI: 10.1039/C7CP01300K

44. Ibupoto, Z. H.; Abbasi, M. A.; Liu, X.; Al Salhi, M. S.; Willander, M. The Synthesis of $\mathrm{NiO}^{-\mathrm{TiO}_{2}}$ Heterostructures and Their Valence Band Offset Determination. J. Nanomater. 2014, 2014, 1, DOI: 10.1155/2014/928658 
45. Ensling, D.; Thißen, A.; Gassenbauer, Y.; Klein, A.; Jaegermann, W. In-Situ Preparation and Analysis of Functional Oxides. Adv. Eng. Mater. 2005, 7, 945-49, DOI: 10.1002/adem.200500125

46. Janczarek, M.; Kowalska, E.; Ohtani, B. Decahedral-shaped Anatase Titania Photocatalyst Particles: Synthesis in a Newly Developed Coaxial-flow Gas-phase Reactor. Chem. Eng. J. 2016, 289, 502-12, DOI: 10.1016/j.cej.2016.01.008

47. Wu, Z.; Zhang, M.; Ge, S.; Zhang, Z.; Li, W.; Tao, K. Synthesis and Characterization of a Porous Amorphous Ni-B Catalyst on Titania by Silver-Catalyzed Electroless Plating. J. Mater. Chem. 2005, 15, 4928- 33, DOI: 10.1039/b510975b

48. Lee, S.-H.; Galstyan, V.; Ponzoni, A.; Gonzalo-Juan, I.; Riedel, R.; Dourges, M.-A.; Nicolas, Y.; Toupance, T. Finely Tuned $\mathrm{SnO}_{2}$ Nanoparticles for Efficient Detection of Reducing and Oxidizing Gases: The Influence of Alkali Metal Cation on Gas-Sensing Properties. ACS Appl. Mater. Interfaces 2018, 10, 10173-84, DOI: 10.1021/acsami.7b18140

49. Brunauer, S.; Emmett, P. H.; Teller, E. Adsorption of Gases in Multimolecular Layers. J. Am. Chem. Soc. 1938, 60, 309-19, DOI: 10.1021/ja01269a023

50. Klein, A.; Green, D. J. Transparent Conducting Oxides: Electronic Structure-Property Relationship from Photoelectron Spectroscopy within Situ Sample Preparation. J. Am. Ceram. Soc. 2012, 96, 331- 45, DOI: 10.1111/jace.12143

51. Uddin, Md. T.; Nicolas, Y.; Olivier, C.; Toupance, T.; Müller, M. M.; Kleebe, H.-J.; Rachut, K.; Ziegler, J.; Klein, A.; Jaegermann, W. Preparation of $\mathrm{RuO}_{2} / \mathrm{TiO}_{2}$ Mesoporous Heterostructures and Rationalization of Their Enhanced Photocatalytic Properties by band Alignmant Investigations. J. Phys. Chem. C 2013, 117, 22098-110, DOI: 10.1021/jp407539c

52. Ahmed, M. A.; Abdel Messih, M. F.; El-Sherbeny, E. F.; El-Hafez, S. F.; Khalifa, A. M. M. Synthesis of Metallic Silver Nanoparticles Decorated Mesoporous $\mathrm{SnO}_{2}$ for Removal of Methylene Blue Dye by Coupling Adsorption and Photocatalytic Processes. J. Photochem. Photobiol., A 2017, 346, 77-88, DOI: 10.1016/j.jphotochem.2017.05.048

53. Ding, J.; Ming, J.; Lu, D.; Wu, W.; Liu, M.; Zhao, X.; Li, C.; Yang, M.; Fang, P. Study of the Enhanced Visible-light-sensitive Photocatalytic Activity of $\mathrm{Cr}_{2} \mathrm{O}_{3}$-loaded Titanate Nanosheets for $\mathrm{Cr}(\mathrm{VI})$ Degradation and $\mathrm{H}_{2}$ Generation. Catal. Sci. Technol. 2017, 7, 2283-97, DOI: 10.1039/C7CY00644F

54. Wen, X.-J.; Niu, C.-G.; Zhang, L.; Zeng, G.-M. Fabrication of $\mathrm{SnO}_{2}$ Nanopaticles/BiOI n-p Heterostructure for Wider Spectrum VisibleLight Photocatalytic Degradation of Antibiotic Oxytetracycline Hydrochloride. ACS Sustainable Chem. Eng. 2017, 5, 5134- 47, DOI: 10.1021/acssuschemeng.7b00501

55. Ahmad, J.; Majid, K. Enhanced visible light driven photocatalytic activity of CdO-graphene oxide heterostructures for the degradation of organic pollutants. New J. Chem. 2018, 42, 3246- 59, DOI: 10.1039/C7NJ03617E

56. Wendt, S.; Sprunger, P. T.; Lira, E.; Madsen, G. K.; Li, Z.; Hansen, J. O.; Matthiesen, J.; Blekinge-Rasmussen, A.; Laegsgaard, E.; Hammer, B.; Besenbacher, F. The Role of Interstitial Sites in the Ti3d Defect State in the Band Gap of Titania. Science 2008, 320, 1755- 9, DOI: 10.1126/science.1159846

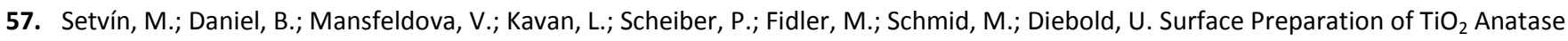
(101): Pitfalls and How to Avoid Them. Surf. Sci. 2014, 626, 61- 7, DOI: 10.1016/j.susc.2014.04.001

58. Thomas, A. G.; Flavell, W. R.; Mallick, A. K.; Kumarasinghe, A. R.; Tsoutsou, D.; Khan, N.; Chatwin, C.; Rayner, S.; Smith, G. C.; Stockbauer, R. L.; Warren, S.; Johal, T. K.; Patel, S.; Holland, D.; Taleb, A.; Wiame, F. Comparison of the Electronic Structure of Anatase and Rutile $\mathrm{TiO}_{2}$ Single-crystal Surfaces using Resonant Photoemission and X-ray Absorption Spectroscopy. Phys. Rev. B: Condens. Matter Mater. Phys. 2007, 75, 035105, DOI: 10.1103/PhysRevB.75.035105

59. Li, M.; Hebenstreit, W.; Diebold, U.; Henderson, M. A.; Jennison, D. R. Oxygen-Induced Restructuring of Rutile $\mathrm{TiO}_{2}(110)$ : Formation Mechanism, Atomic Models, and Influence on Surface Chemistry. Faraday Discuss. 1999, 114, 245- 58, DOI: 10.1039/a903598b

60. Wu, C. C.; Wu, C. I.; Sturm, J. C.; Kahn, A. Surface Modification of Indium Tin Oxide by Plasma Treatment: An Effective Method to Improve the Efficiency, Brightness, and Reliability of Organic Light Emitting Devices. Appl. Phys. Lett. 1997, 70, 1348- 50, DOI: 10.1063/1.118575

61. Klissurski, D.; Hadjiivanov, K.; Kantcheva, M.; Gyurova, L. Study of Peroxide-Modified Titanium Dioxide (Anatase). J. Chem. Soc., Faraday Trans. 1990, 86, 385- 88, DOI: 10.1039/ft9908600385

62. Cullity, B. D. Answers to Problems: Elements of X-Ray Diffraction; Addison-Wesley Publishing Co.: 1978.

63. Patil, P.; Kadam, L. Preparation and Characterization of Spray Pyrolyzed Nickel Oxide (NiO) Thin Films. Appl. Surf. Sci. 2002, 199, 21121, DOI: 10.1016/S0169-4332(02)00839-5

64. Sawatzky, G.; Allen, J. Magnitude and Origin of the Band Gap in NiO. Phys. Rev. Lett. 1984, 53, 2339, DOI: 10.1103/PhysRevLett.53.2339

65. Sreethawong, T.; Ngamsinlapasathian, S.; Yoshikawa, S. Surfactant-Aided Sol-Gel Synthesis of Mesoporous-Assembled TiO ${ }_{2}-\mathrm{NiO}$ Mixed Oxide Nanocrystals and Their Photocatalytic Azo Dye Degradation Activity. Chem. Eng. J. 2012, 192, 292- 300, DOI: 10.1016/j.cej.2012.04.006

66. Nolan, M.; Iwaszuk, A.; Lucid, A. K.; Carey, J. J.; Fronzi, M. Design of Novel Visible Light Active Photocatalyst Materials: Surface Modified $\mathrm{TiO}_{2}$. Adv. Mater. 2016, 28, 5425-46, DOI: 10.1002/adma.201504894

67. Diebold, U. The Surface Science of Titanium Dioxide. Surf. Sci. Rep. 2003, 48, 53-229, DOI: 10.1016/S0167-5729(02)00100-0

68. Zhang, Y.-f.; Lin, W.; Li, Y.; Ding, K.-n.; Li, J.-q. A Theoretical Study on the Electronic Structures of $\mathrm{TiO}_{2}$ : Effect of Hartree-Fock Exchange. J. Phys. Chem. B 2005, 109, 19270- 77, DOI: 10.1021/jp0523625

69. Makula, P.; Pacia, M.; Macyk, W. How to Correctly Determine the Band Gap Energy of Modified Semiconductor Photocatalysts Based on UV-Vis Spectra. J. Phys. Chem. Lett. 2018, 9, 6814-17, DOI: 10.1021/acs.jpclett.8b02892

70. van Veenendaal, M. A.; Sawatzky, G. A. Nonlocal Screening Effects in $2 p$ X-Ray Photoemission Spectroscopy Core-Level Line Shapes of Transition Metal Compounds. Phys. Rev. Lett. 1993, 70, 2459- 62, DOI: 10.1103/PhysRevLett.70.2459 
71. Soriano, L.; Preda, I.; Gutiérrez, A.; Palacín, S.; Abbate, M.; Vollmer, A. Surface Effects in the Ni2p X-Ray Photoemission Spectra of NiO. Phys. Rev. B: Condens. Matter Mater. Phys. 2007, 75, 233417, DOI: 10.1103/PhysRevB.75.233417

72. Zhang, T.; Oyama, T.-K.; Horikoshi, S.; Hidaka, H.; Zhao, J.; Serpone, N. Photocatalyzed N-Demethylation and Degradation of Methylene Blue in Titania Dispersions Exposed to Concentrated Sunlight. Sol. Energy Mater. Sol. Cells 2002, 73, 287- 303, DOI: 10.1016/S0927-0248(01)00215-X

73. Zhang, T.; Oyama, T.-K.; Aoshima, A.; Hidaka, H.; Zhao, J.; Serpone, N. Photooxidative N-demethylation of methylene blue in aqueous $\mathrm{TiO}_{2}$ dispersions under UV-irradiation. J. Photochem. Photobiol., A 2001, 140, 163- 72, DOI: 10.1016/S1010-6030(01)00398-7

74. Selloni, A. Anatase Shows Its Reactive Site. Nat. Mater. 2008, 7, 613-15, DOI: 10.1038/nmat2241 